Portland State University

PDXScholar

Fall 12-15-2015

\title{
Engineering a Healthier Watershed: Middle School \\ Students Use Engineering Design to Lessen the Impact of Their Campus' Impervious Surfaces on Their Local Watershed
}

Elizabeth Claire Gardner

Portland State University

Follow this and additional works at: https://pdxscholar.library.pdx.edu/open_access_etds

Part of the Environmental Education Commons, and the Water Resource Management Commons Let us know how access to this document benefits you.

\section{Recommended Citation}

Gardner, Elizabeth Claire, "Engineering a Healthier Watershed: Middle School Students Use Engineering Design to Lessen the Impact of Their Campus' Impervious Surfaces on Their Local Watershed" (2015). Dissertations and Theses. Paper 2634.

https://doi.org/10.15760/etd.2630

This Thesis is brought to you for free and open access. It has been accepted for inclusion in Dissertations and Theses by an authorized administrator of PDXScholar. Please contact us if we can make this document more accessible: pdxscholar@pdx.edu. 
Engineering a Healthier Watershed: Middle School Students Use Engineering Design to Lessen the Impact of Their Campus' Impervious Surfaces on Their Local Watershed

\title{
by
}

Elizabeth Claire Gardner

A thesis submitted in partial fulfillment of the requirements for the degree of

\author{
Master of Science in Teaching \\ in \\ General Science
}

Thesis Committee:

William Becker, Chair

Stephanie Wagner

Melissa Potter

Portland State University

2015 


\begin{abstract}
It is important that students understand not only how their local watershed functions, but also how it is being impacted by impervious surfaces. Additionally, students need experience exploring the scientific and engineering practices that are necessary for a strong STEM background. With this knowledge students can be empowered to tackle this real and local problem using engineering design, a powerful practice gaining momentum and clarity through its prominence in the recent Framework for K-12 Science Education. Twenty classes of suburban sixth-graders participated in a new five-week Watershed Engineering Design Unit taught by their regular science teachers. Students engaged in scientific inquiry to learn about the structure, function, and health of their local watersheds, focusing on the effects of impervious surfaces. In small groups, students used the engineering design process to propose solutions to lessen the impact of runoff from their school campuses. The goal of this evaluation was to determine the effectiveness of the curriculum in terms of student gains in understanding of (1) watershed function, (2) the impact of impervious surfaces, and (3) the engineering design process. To determine the impact of this curriculum on their learning, students took multiple-choice pre- and post-assessments made up of items covering the three categories above. This data was analyzed for statistical significance using a lower-tailed paired sample $t$-test. All three objectives showed statistically significant learning gains and the results were used to recommend
\end{abstract}


improvements to the curriculum and the assessment instrument for future iterations.

Keywords: watershed education, engineering design education, curriculum, middle school 


\section{Acknowledgements}

There are many wonderful people I would like to thank for their expertise, guidance, support, and endurance throughout my time with the MST program.

Associated with the Portland State University Center for Science Education: the truly amazing Stephanie Wagner, who brought together all of the necessary parties to make the WEDU happen, taught me, lead me, assisted me, encouraged me, and dove in and got her hands dirty at every turn; Melissa Potter, who encouraged me with smiles and constructive feedback, and excited and challenged me with new ideas; Cary Sneider, who patiently guided me through the first half of my thesis, pointing me in all the right directions; Bill Becker, who kindly joined my thesis committee and helped me improve my paper; Riley Meinershagen, who began the WEDU before me, and Lecia Schall, who continued the work after I returned to my own classroom; the MST colleagues who contributed by vetting assessment questions and previewing drafts; Mark Blackmore, who facilitated my use of statistics; and my tireless writing coach, Daveena Tauber, who expertly sliced my otherwise insurmountable thesis project into manageable chunks and stuck with me through multiple drafts. Thank you all.

From the greater community for which the WEDU was created: Matthew Collins, who took me on as an intern and taught me a great deal about outdoor education and the beautiful natural areas right outside my window; the good people of a local natural area organization and the local watershed 
stewardship organization, who supported my research and my learning

objectives through dedication of resources and education of the public, and the many people who have donated time and resources to keep those organizations thriving. Thank you all.

From the cooperating school district: thank you to the administration for partnering with us, the pilot year teachers for trusting us and doing a terrific job with little lead time, the students who participated in the WEDU, and 439 parents who gave us access to their data - without all of you, there would have been no project. Thank you all.

And last but certainly not least, my family: Sara, who shouldered far more of the work and stress than one person should ever have been asked to handle; Sally, Paula, and Dave, who picked up some of my slack and kept our family functioning; and Eddie, who was born on the first day of my master's program and turned three before its completion, and reminded me daily to be a life-long learner. Thank you all for your incredible support, encouragement, and endurance. 


\section{Table of Contents}

Abstract $\ldots \ldots \ldots \ldots \ldots \ldots \ldots \ldots \ldots \ldots \ldots \ldots \ldots \ldots \ldots \ldots$

Acknowledgements .........................

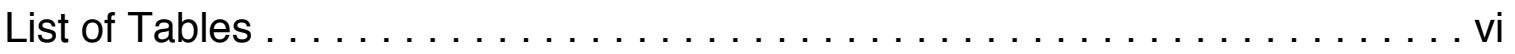

List of Figures $\ldots \ldots \ldots \ldots \ldots \ldots \ldots \ldots \ldots \ldots \ldots \ldots \ldots \ldots \ldots \ldots \ldots \ldots \ldots$

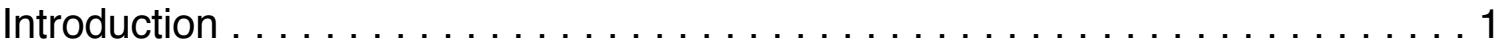

Literature Review $\ldots \ldots \ldots \ldots \ldots \ldots \ldots \ldots \ldots \ldots \ldots \ldots \ldots$

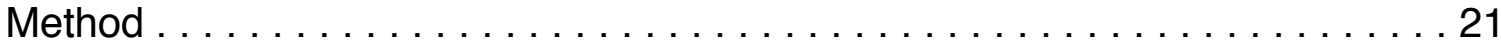

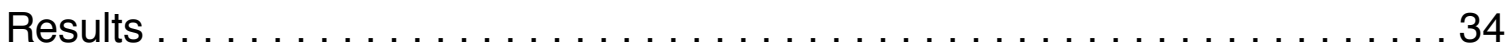

Limitations and Delimitations $\ldots \ldots \ldots \ldots \ldots \ldots \ldots \ldots \ldots \ldots \ldots$

Discussion and Recommendations $\ldots \ldots \ldots \ldots \ldots \ldots \ldots \ldots \ldots \ldots$

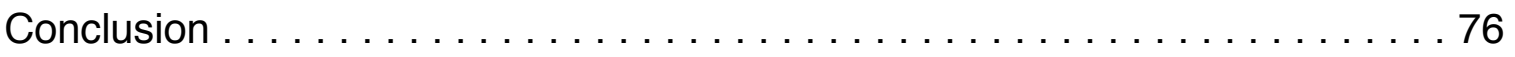

References ............................ 79

Appendices

A: Student Participation Consent Form $\ldots \ldots \ldots \ldots \ldots \ldots \ldots \ldots$.

B: Watershed Engineering Design Unit Alignments . . . . . . . 84

C: Watershed Engineering Design Unit Assessment $\ldots \ldots \ldots \ldots \ldots 8$ 


\section{List of Tables}

1: Progression of Lessons by Objective in the Watershed

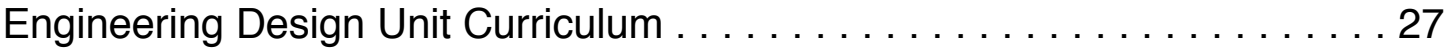

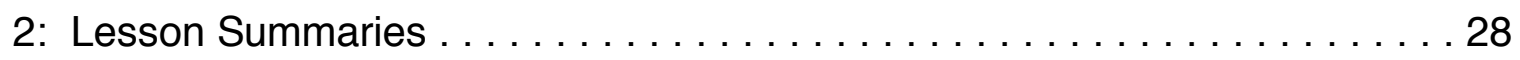

3: Pre- and Post-Assessment Analysis by Objective ............ 36

4: Pre- and Post-Assessment Analysis by Individual Question . . . . . . . . 38 


\section{List of Figures}

1: Objective 1 Strengths $\ldots \ldots \ldots \ldots \ldots \ldots \ldots \ldots \ldots \ldots \ldots \ldots 49$

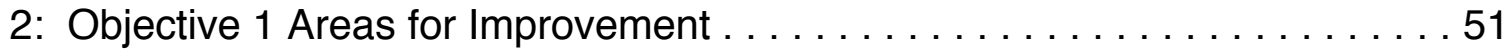

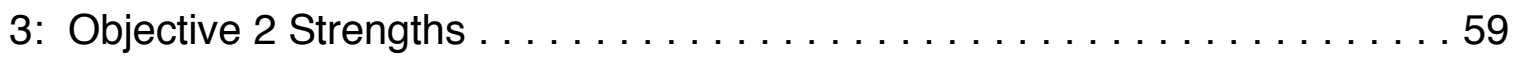

4: Objective 2 Areas for Improvement $\ldots \ldots \ldots \ldots \ldots \ldots \ldots \ldots \ldots \ldots 60$

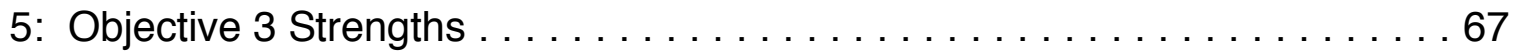

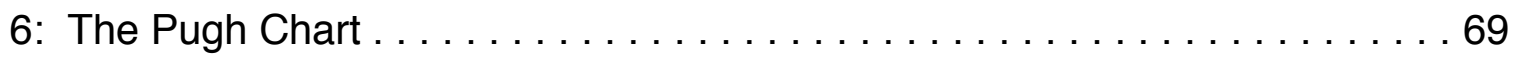

7: Objective 3 Areas for Improvement $\ldots \ldots \ldots \ldots \ldots \ldots \ldots \ldots \ldots \ldots$ 


\section{Introduction}

The current push for STEM (science, technology, engineering, and mathematics) education has been at the forefront of $\mathrm{K}-12$ education discussions for several years, but until recently engineering has not been given nearly the attention as its fellow STEM fields. Two recent publications, A Framework for K12 Science Education: Practices, Crosscutting Concepts, and Core ideas and the earlier Engineering in K-12 Education: Understanding the status and improving the prospects call for more engineering education in the $\mathrm{K}-12$ arena and further research into the efficacy of the engineering curriculum and pedagogy in use. One way to emphasize the E in STEM is to use an integrated approach by having students learn engineering design while employing it to solve place-based problems. In this study, middle school students first used scientific inquiry to recognize the problems posed to their local watersheds by the expanses of impervious surfaces covering portions of their school campuses. With those problems in mind, students then engaged in engineering design to propose solutions to mitigate the effects of impervious surfaces on the local watershed.

Whether you live in a flat region with a dry climate, amidst skyscrapers in a mostly-paved urban city center, or at the top of a rainy, wooded hillside, you live in a watershed. Most Americans do not know what a watershed is, let alone the destruction that mismanaged stormwater can cause. The city in which this study took place has an active watershed council that counts among its mission tenets watershed conservation, restoration, and education. The city and its watershed 
council have a vested interest in educating their youth to become thoughtful and proactive caretakers of the watershed. The watershed council advocated for and partially funded the development of the watershed-themed curriculum that we piloted during the 2012-2013 school year. That curriculum, the Watershed Engineering Design Unit, or WEDU, is the focus of this evaluation.

The purpose of this curriculum project was two-fold. The first was for suburban sixth-grade students to learn about watershed function and the impacts impervious surfaces such as roads, roofs, and parking lots have on the health of our watersheds. The second was to engage them in the practice of engineering design with the goal of proposing solutions to mitigate the effects of their campus' impervious surfaces on their local watershed. Although there is scholarly work available on the topics of watershed education and engineering design independently, our work seeks to bring the two together through a case study examining the efficacy of the first iteration of the curriculum.

Following a constructivist approach, we developed the WEDU to meet the needs of a specific affluent, suburban, northwestern school district. The 20122013 school year was the school's first year of changing from a K-6 model to one that places sixth-grade students at the middle school level. To fulfill state requirements, the school district needed to incorporate an engineering design experience complete with work sample. Our team of university faculty and graduate students developed the WEDU in partnership with the school district, 
the local watershed council, and a local non-profit community organization dedicated to conservation, education, and recreation.

In this 24-lesson, five-week unit, students reviewed and learned about how a watershed functions as part of a natural system, then examined human impacts on their own watershed, specifically those posed by impervious surfaces. After investigating the impervious surfaces on their school campus, students used the engineering design process to develop proposed solutions to address the problem of runoff generated by their campus. Upon completing the unit, students presented their final designs as well as completed an engineering design work sample as required by the state department of education. Brief summaries of each lesson can be found on pages 28-29.

The purpose of this case study was to evaluate the WEDU in terms of students' gains in understanding of three main learning objectives listed within the research question. To what degree did participation in the new Watershed Engineering Design Unit increase student knowledge of (1) watershed function, (2) the impacts of impervious surfaces, and (3) the engineering design process? For the purpose of this study the independent variable is student participation in the WEDU and the dependent variable is the gain in student knowledge. The classroom teachers administered the 17 question multiple-choice assessment to the students immediately before and after teaching the unit. Student understanding of the above learning objectives was measured by the difference between the pre- and post-assessment scores of 266 students. Using the data 
we analyzed the assessments to answer the research question. Results will inform future iterations of the curriculum and the assessment instrument. 


\section{Literature Review}

Independent of one another, the benefits of watershed education and engineering design have both been documented in the literature. The literature, however, does not address bringing watershed education together with engineering design in a $\mathrm{K}-12$ setting. This literature review examines the bodies of literature related to watershed education and engineering design education. Ultimately, the purpose of this study is to document the use of engineering design within watershed education as a tool for learning as well as empowering students to make real improvements to their environments.

\section{Watershed Place-Based Education}

Evidence of K-12 students participating in watershed education began to emerge in academic journals in the late 1990s. Donahue et al. (1998) documented one of the first instances of organized watershed education-the efforts of the then not-yet decade-old Global Rivers Environmental Education Network, or GREEN. Beginning with a 1984 hepatitis outbreak among Huron River windsurfers, high school students joined forces with teachers and university professors from Ann Arbor, Michigan to gather and analyze watershed data. Together they uncovered and addressed the problem of raw sewage contaminating the river after storm events. Soon the watershed education model that would become known as GREEN caught on in neighboring regions and within 15 years GREEN's constructivist, student-centered watershed education programs had spread to 130 countries. Donahue et al. share details of GREEN 
case studies from Curl Curl Lagoon in Sydney, the Rouge River watershed in Detroit, the Thornton Creek watershed in Seattle, and the Harpeth River watershed in Tennessee. This diversity of settings allowed GREEN to distill the success of student-scientist partnerships, or SSPs, to four education elements that include: use an inquiry-based approach; build around authentic, communitybased investigations; let students be scientists; and allow scientists to be educators (p. 16).

Donahue et al. conclude:

[S]tudents must become scientists in their communities. This occurs...as students move beyond the walls of the schools to conduct authentic investigations, and work with their scientist partners to develop and apply science skills and knowledge in the service of their communities. The GREEN approach to watershed education, incorporating student-scientist partnerships, provides a powerful model for both the content and process of learning. ( $p$. 23)

Donahue et al. and GREEN were among the trailblazers who helped to establish watershed education.

Shepardson et al. (2007) recognized the work of programs such as GREEN while identifying a concern requiring further research. Shepardson et al. noted that other studies have investigated children's environmental attitudes or their factual knowledge of watersheds, but minimal data were available in respect to student conceptions of watersheds. The authors believe that understanding student conceptions of watersheds is key if one is to create a learning progression or curriculum that builds on what students believe as well as recognizes and addresses student misunderstandings. As of 1999 , "only $41 \%$ of 
adults have any idea what a watershed is, only $22 \%$ know that storm water runoff is a major cause of stream pollution within a watershed" (Shepardson et al., 2007), which highlights the need for more effective watershed education (p. 556). The authors note that watershed concepts introduce many important water issues, including the ideas of water as resource and of water pollution, both of which offer an opportunity to get children more involved in and excited about their local watersheds. A greater awareness could lead students to make more informed decisions as adults and perhaps become more protective of their watersheds.

Shepardson et al. used White and Gunstone's established draw-andexplain protocol (1992) to elicit student drawings and written explanations of what a watershed is from 915 students from various academic settings in grades four through 12. Following Rubin and Rubin's (1995) analytical procedure, the researchers coded student watershed conceptions and analyzed those conceptions using a matrix. They arrived at themes and finally:

[F]our categories of student conceptions about watersheds. Conception 1: Watershed as a natural and dynamic process consisting of a developed hydrologic cycle. Conception 2: Watershed as a natural process containing elements of the hydrologic cycle. Conception 3: Watershed as the natural storage of water (i.e., bodies of water-lake or pond). Conception 4: Watershed as a human-built facility for storing water (e.g., water stored in a "shed" or "tower") (p. 560).

The first three conceptions include a natural process creating storage in a natural environment. Conception 1, which represented $29 \%$ of student responses, was the most accurate and complete. The last conception indicates a belief that a 
watershed is a man-made structure, the only entirely erroneous conception, which accounted, significantly, for $46 \%$ of student responses. Among students depicting a watershed as a natural system, there was frequently an overemphasis on extreme topography and the evaporation-condensationprecipitation cycle, and an underrepresentation of the existence of groundwater or human interactions with a watershed. These same students generally avoided urban and man-made structures and impacts in their drawings and descriptions. From their findings, Shepardson et al. compiled a list of 11 concepts that they recommend be explicitly taught to students as an important component of developing an understanding of watersheds as well as a table demonstrating the alignment between watershed concepts and the 1996 National Science Education Standards (National Research Council, 1999).

Published in 2009, Endreny's article chronicles her research, which took a place-based approach to teaching 33 urban fifth graders about their local watershed. The unit extended from October through March, pursuing the research questions “(1) What were the children's conceptions before and after the unit? (2) How did place-based inquiry influence the students' conceptions of the watershed?" (p. 504). Through a recounting of the literature, the author explains the benefits of place-based education such as the opportunity to construct knowledge first-hand while working on real and relevant problems, and the positive effects on student attitudes and performance. Endreny's reference to watershed literature pulls heavily from a couple of articles by Shepardson et al., 
using their 2007 article as a basis for her lesson objectives, which seek to satisfy the National Science Education Standards circa 1996 (National Research Council).

Endreny, acting as teacher-researcher, taught a "place-based inquiry unit on watersheds" to two classes, utilizing the regular classroom teachers in assisting roles. Using structured inquiry, the researcher collected qualitative data from students in the form of concept maps, science notebooks, and interviews, as well as replicated Shepardson et al.'s "watershed task" before and after the unit. In the text as well as multiple tables, Edreny shares her findings in detail. Some results show a minority of the students demonstrating understanding of a concept, others show a majority, but without a clear before and after side-by-side comparison, I found it hard to know exactly what was gained as a direct result of implementing the unit. What is clear, though, is that every student made progress of some kind, all students understood their urban area to be a part of a watershed, and all could explain some forms of pollution found within the watershed. The author concludes, "this study illustrated how an urban setting can be used to study the local natural attributes of a place. It was found that placebased education can positively influence standards-based curricula instead of detract from it" (p. 515).

Covitt, Gunckel, and Anderson (2009) investigated the differences between what students think is happening in natural and man-made water systems and what is scientifically accurate. The main goals of the research were 
to investigate students' thinking about the movement of water and other substances through natural and manmade systems, both visible and invisible. (p. 40) Designing their instrument as a stand-alone assessment not tied to a unit of study, the researchers asked students questions about water in different forms and different places to investigate their ideas. In the 2005-2006 school year the researchers asked questions of students in grades three through 12. The 561 assessments that they received were comprised of short written answers and drawn pictures. Focusing on a subset of 20 assessments, Covitt, Gunckel, and Anderson created a rubric by taking turns categorizing and coding student answers until a final rubric was created. That rubric was used to score a representative sample of 120 assessments (40 each of elementary, middle, and high school) with inter-rater reliability of $\geq .75$. The instruments and data from this study, along with materials from subsequent iterations, is available online.

What Covitt, Gunckel, and Anderson found was that students' understanding were largely limited to what they could directly observe, leaving out large scale systems like watersheds and micro-systems like molecules in solution, as well as water hidden from view in pipes or by infiltration or evaporation. Students were frequently incorrect about how pollution travels, often not recognizing the role of water in the process. Most pertinent to my research was the finding that when shown a map of surface waters and asked about the transmission of a hypothetical pollutant, "only $5 \%$ of middle school students and about $17.5 \%$ of high school students explained how water moves in a watershed 
system" (p. 43). The researchers attribute these inaccuracies to the fragmentary way that water is studied in $\mathrm{K}-12$ education in which the water cycle is covered as part of earth and space science; phase changes are covered in physics; and dissolved solutions studied in chemistry. In this model, important ideas such as groundwater are often completely missing (p. 49). They recommend that curriculum be designed that better connects the various water systems, beginning with a solid foundation about how water moves, and that models should be used whenever possible, especially to demonstrate groundwater, watersheds, and evaporation.

In summary, many people have contributed key ideas to the literature on place-based watershed education over the past few decades. Covitt, Gunckel, and Anderson (2009) clearly articulated the need for watershed education when they wrote:

The need to protect water quality and distribution provides an impetus for developing science education that prepares people to be competent decision makers about water systems. ... Understanding how water moves through environmental systems and interacts with other substances is critical for making informed decisions about water at an individual or societal level (p. 37).

Donahue et al. (1998) introduced us to the history, inquiry, success, and place-based nature of watershed education, opening the door for further research. Shepardson et al. (2007) demonstrated that most students do not have accurate conceptions of watersheds and suggested that watershed concepts need to be taught explicitly. Building on Shepardson et al.'s work 
and using the same instrument, Endreny (2009) showed that students could make gains in their understandings of watersheds after an inquiry unit. Covitt, Gunckel, and Anderson (2009) honed in on the difficulty K-12 students have in understanding groundwater and other movement of water that students cannot easily observe firsthand. Among their suggestions was the use of models. These authors offer a consensus within the literature that students need explicit instruction about watersheds and groundwater and that the use of place-based inquiry and modeling are effective.

\section{Engineering Design Education}

The second section of this literature review seeks to explore engineering design education (including the use of models) as it could be used in tandem with watershed education. In 2009, the National Academy of Engineering (NAE) and the National Research Council (NRC) published a book called Engineering in K-12 Education: Understanding the status and improving the prospects (NAE and NRC, 2009). The authors assessed the current state of engineering education in our nations $\mathrm{K}-12$ system by defining it, discussing the need for it, reviewing much of the current curricula and pedagogy in use, and making recommendations for where engineering education should head moving forward. The authors named three research questions:

- What are realistic and appropriate learning outcomes for K12 engineering education? 
- How might engineering education complement the learning objectives of other content areas, particularly science, technology, and mathematics, and how might these other content areas compliment learning objectives in engineering education?

- What educational policies, programs, and practices at the local, state, and federal levels might lead to the meaningful inclusion of engineering in $\mathrm{K}-12$ education in the United States? (p. 21)

Throughout the literature surrounding engineering education there exists a multitude of theories and claims regarding the benefits of its inclusion in $\mathrm{K}-12$ education. However, most of these ideas remain undefended due in part to the relative lack of high-quality data available (p. 51). Toward the claim of using engineering to improve student achievement in math and science, the authors of Engineering in K-12 Education (NAE and NRC, 2009) summarize, "available evidence suggests that under certain circumstances, engineering education can boost learning and achievement... [h]owever, the positive effects are not universal and research has not clearly established the causal mechanism(s) to explain such benefits when they occur" (p. 55). Further research is needed in this area.

Engineering education, as it currently exists, is experiencing a great variety of definitions for terms such as 'analysis' and 'modeling,' and this book offers some as well. The authors refer to Standards for Technological Literacy: Content for the Study of Technology (ITEA, 2000) for an explanation of engineering design, a subcategory of engineering education. By their 
definition, engineering design is purposeful, guided by specifications and constraints, systematic, iterative, collaborative, and non-linear with the opportunity for multiple solutions (p. 38). When the NAE and NRC distilled their research down to findings and recommendations, the first principal was:

Principle 1. K-12 engineering education should emphasize engineering design. The design process, the engineering approach to identifying and solving problems, is (1) highly iterative; (2) open to the idea that a problem may have many possible solutions; (3) a meaningful context for learning scientific, mathematical; and technological concepts; and (4) a stimulus to systems thinking, modeling, and analysis. In all of those ways, engineering design is a potentially useful pedagogical strategy. (p. 151).

The authors also call for a more integrated approach to teaching STEM subjects, going so far as to say, "for engineering education to become more than an afterthought in elementary and secondary schools in this country, STEM education as a whole must be reconsidered" (p. 167).

Standing on the shoulders of Engineering in K-12 Education and several other publications, particularly Science for All Americans (American Association for the Advancement of Science, 1990) and Benchmarks for Science Literacy (American Association for the Advancement of Science, 1993), and the National Science Education Standards (NRC, 1996), the National Research Council released another book, A Framework for K-12 Education: Practices, Crosscutting Concepts, and Core Ideas (NRC, 2012). This book provides the structure, progressions, and consensus of ideas and 
practices that the engineering education movement needs. Providing guidance for science and engineering, the NRC framework aims to elevate American science and engineering education to the levels necessary to tackle the challenges we faces as individuals and as a nation.

Rather than attempt to create an exhaustive list of science facts for students to memorize, NRC's framework is built on three dimensions: the practices of science and engineering students will use to engage with content; the crosscutting concepts that show connections between unifying themes in varying disciplines of science; and the disciplinary core ideas, the 13 most important, useful, relevant ideas that can be learned in stages over a K-12 education. One of those 13 core ideas is engineering design.

Taking cues from the engineering design elements of the NRC's framework (2012) and modifying a pre-existing science unit on the human heart, author-researchers Foster and Ganesh (2013) created a two-week sixth-grade science bioengineering design challenge unit. Including engineering design doubled the time required to teach the science content. Working in conjunction with the classroom teachers, the researchers taught 32 students who worked in groups of four. Foster and Ganesh developed science learning objectives from the teacher's existing science curriculum, as well as Engineering Practices, Crosscutting Concepts, and Disciplinary Core Idea learning objectives from the NRC's framework (NRC, 2012). 
The researchers collected both quantitative and qualitative data.

Quantitative data focused primarily on the form and function of the heart, and, utilizing a paired samples $t$-test, showed statistically significant differences for three of four learning objectives. For qualitative data the researchers interviewed students groups before, during, and after the unit to better observe the students' understanding of main science and engineering concepts. Foster and Ganesh also used the unit's learning objectives to guide semi-structured interviews, as well as collected models and notebooks. Using these measures, the researchers found that between $62.5 \%$ and $100 \%$ of the eight student groups met each engineering design learning objective respectively. In conjunction with further analysis of their results, the researchers intend to revise and extend the unit for its next use as well as utilize a control group.

During Foster and Ganesh's human heart unit (2013), students worked with physical models. In Klahr, Triona, and Williams (2007) study, students also worked with models to accomplish an engineering task, but some students built and tested physical models while others explored the same task using computerized virtual models. Although we often hear of the benefits of "hands-on" activities, "critics of hands-on activities argue that they make learning less efficient and effective by producing confusing and inconsistent feedback.... Moreover, hands-on instruction tends to have higher logistical, financial, and temporal costs when compared with other approaches (Hodson, 1996)" (pg. 184). Through the use of a table, the 
researchers identify important distinctions within the various kinds of engineering tasks. The instructional goals of the task can either be domaingeneral knowledge or domain-specific knowledge, within those categories the students can engage in either direct instruction or a discovery learning, and within any combination of the above options a student may find himself in a hands-off environment or working with hands-on materials, be they physical or virtual (p. 185). Klahr, Triona, and Williams argue that most of the research into the physical versus virtual comparison are confounded by a lack of holding constant all other variables. For the purpose of their experiment, all students would be working toward gaining domain-specific knowledge using a discovery learning mode and hands-on materials. With those constants, Klahr, Triona, and Williams were confident the results would isolate the variable of physical versus virtual engineering design models. Klahr, Triona, and Williams (2007) described their task as follows:

Seventh and eighth grade children engaged in an engineering design task in which they created and tested a series of "mousetrap cars": small mobile cars powered by an ordinary mousetrap that can travel dozens of feet... The children's challenge was to discover the combination of features that yielded an optimal design for the car that could travel the farthest... [The mousetrap cars'] ultimate purpose is to provide a highly motivating context in which students can learn about conservation of energy, torque, friction, and mechanical advantage" (p. 187).

Given the options of car body lengths, rear axel thicknesses, front and rear wheel options, there were 36 distinct combinations. Of the two groups of 
children in the experiment, one group's procedure was to choose their combination of components, assemble them, run them on the floor in a hallway, and collect the data. The other group's procedure was to click on the attributes they wanted, assemble them within the computer program, and "run" them in a virtual computer simulation which showed an animation of a car moving across the screen and numbers representing the distance traveled ( $p$. $187,192)$. Both groups then either disassembled their physical cars or "reset" their virtual cars and built another car. To account for differences in the time it takes to build and test a physical car as compared to a virtual car, within each condition were groups with a fixed-time time of 20 minutes within which to build and test as many cars as possible, and groups with a fixed-number of cars who were limited to building and testing a total of six cars.

Children were quizzed on which car features contribute to a faster car both before and after their experimentation. The researchers found that both groups, physical and virtual, showed significant gains in knowledge of the causal variables. Though the groups working with the virtual materials scored somewhat higher than those using the physical materials, the difference between them was not statistically significant. Klahr, Triona, and Williams (2007) found that the only advantage the physical material students had was, on average, more substantive responses when asked what else might improve the distance of the car:

[S]uch as: "Make sure the car goes straight"; "Let the string come loose from the axel after it fully unwinds so the car can free roll"; or "Make sure the surface of the floor is smooth."... Of all the 
measures, this was the only one for which an advantage for physical materials approached significance. Although children in the virtual condition had no direct experience with such things as running the cars on a smooth floor or cars veering off to the left of the right, their responses to this final question were no worse than those of children in the physical condition. (p. 194-195)

As their findings revealed a lack of a difference in performance between physical and virtual hands-on engineering design, educators are able to look to other factors when deciding what kind of hands-on engineering design experience to offer their students. Possible advantages of virtual models include easier implementation given lesser demands of space, time, and cost (p. 198).

In review, Engineering in K-12 Education (NAE and NRC, 2009) called attention to the growing body of $\mathrm{K}-12$ engineering education taking place in the United States, the opportunity to integrate engineering with other STEM fields, and the need for further research into the popular claims made regarding existing engineering design programs and pedagogy so that we may improve them. The NAE and NRC recognized the value of engineering design and endorse its emphasis in the K-12 domain. A Framework for K-12 Science Education (NRC, 2012) stepped in to provide a holistic framework for how to restructure and improve science and engineering education in our schools nationwide. Using that very framework, Foster and Ganesh (2013) demonstrated gains in student learning by incorporating engineering design into a sixth-grade science unit. Klahr, Triona, and Williams (2007) used hands-on engineering design to investigate the efficacy of virtual models as compared to their physical 
counterparts. They found that both groups made statistically significant gains and that, though there may be some limitations to virtual models, there may also be some advantages. The important points that I took away from the existing research are that engaging students in engineering design is an effective component in teaching science concepts, and that both physical and virtual models are successful tools in engineering design units.

My curriculum brings together place-based watershed education with the practices of engineering design. Students develop an understanding of the unseen processes at work in a watershed as they design solutions that interact with those processes. Students engage with models and collaborate as they develop solutions to mitigate the effects of stormwater on their school campuses. To assess students in both the content area of watersheds and the process skills of engineering design, we developed a multiple-choice pre- and post-assessment tool. Many of the questions on the assessment align with the application of STEM conceptual knowledge construct as described by the STEM Common Measurement System (Saxton et al., 2014). Data from this assessment drove the evaluation of this new curriculum. In turn, this evaluation builds a bridge between watershed education and engineering design education. 


\section{Method}

\section{Overview}

The research question driving the evaluation of the curriculum used in this project was straightforward: To what degree did participation in the new sixthgrade watershed and engineering design unit increase student knowledge of:

(1) watershed function;

(2) the impacts of impervious surfaces;

(3) the engineering design process?

These subsections of the research question also highlight the three main learning objectives.

In order to measure student gains in these areas of understanding, classroom teachers administered a 17 question multiple-choice pre-assessment $\left(\mathrm{O}_{\text {Pre }}\right)$ to all students before teaching the unit (the treatment, $\mathrm{X}$ ), and readministered the same assessment at the end of the experience as a postassessment $\left(\mathrm{O}_{\text {Post }}\right)$. All of the district's sixth-grade students participated in the WEDU. Therefore this study did not have a control or comparison group.

Diagram of study:

$\underline{O}_{\text {Pre }} \mathrm{XO}_{\text {Post }}$

Comparing the results from the pre- and post-assessments (by individual student, by specific question, by objective, and in the aggregate) allowed me to run calculations such as $t$-tests in order to evaluate the data for statistical significance and look for trends that indicate strengths and weaknesses in the 
curriculum and the assessment instrument. This information is critical to making recommendations for future iterations of the curriculum and an improved instrument.

\section{Participants}

The included school district is an affluent suburb of a large city in the Pacific Northwest. The city and both of its middle schools are set near several bodies of water, which gave relevance to topic of watershed health. Both "Basin" and "Catchment"1 Middle Schools have large campuses with substantial areas of impervious surface that include buildings, parking lots, blacktop areas, paved and covered walkways, etc., as well as vast areas of pervious surfaces predominantly covered by grass turf. Basin Middle School (BMS) has a natural seasonal bioswale at the edge of campus and Catchment Middle School (CMS) has easy access to a creek just off campus.

During the $2012-2013$ school year $92.7 \%$ of Basin Middle School eighthgrade students and $88.6 \%$ of Catchment Middle School eighth-graders met or exceeded state benchmarks on the standardized science assessment (sixthgrade students do not take state science assessments). Combined, the two schools had a total of 514 sixth-grade students, $24 \%$ of whom identified as black, Hispanic, Asian/Pacific Islander, American Indian/Alaskan Native, or multi-ethnic, and $76 \%$ of whom identified as white. Fourteen percent of the district's middle

\footnotetext{
${ }^{1}$ School names have been replaced with pseudonyms
} 
school population qualify for free or reduced lunch. At both schools the average years of teaching experience was greater than 10 .

The year of the study the school district changed from a K-6 and junior high model to a K-5 and middle school model. With sixth graders now a part of the middle school, there was a need for adequate and aligned sixth-grade curriculum. This curriculum was created in order to fulfill the state requirement for an engineering design work sample and the city's request for watershed education.

Four teachers, Ms. Miller and Mr. Wilson at BMS and Ms. Brown and Mr. Davis $^{2}$ at CMS, taught the newly formed sixth-grade science classes and with it, the curriculum described in this study. Within each school there was one teacher who had taught seventh- or eighth-grade science in the building the year prior (Wilson and Davis) and one teacher who moved to the middle school from teaching a self-contained fifth- and sixth-grade blended classroom the at one of the district's elementary schools the year before (Miller and Brown). Although all four teachers worked from a mutually agreed upon yearlong curriculum plan, all of the teachers said that they worked together to plan and prepare materials with the other sixth-grade science teacher in their building, but that the four of them did not often get time to come together to collaborate.

All of the school district's sixth-grade classes used the new curriculum and were therefore administered the same treatment. There was no control or

\footnotetext{
${ }^{2}$ Teacher names have been replaced with pseudonyms
} 
comparison group for this study. Between the two middle schools there were 20 pre-established classrooms with class sizes ranging from 21-36 students each. For much of the unit, students work predominantly as part of four- to six-student Engineering Design Teams. In order to use student assessment data, all 514 students took home information sheets outlining the study and requesting permission to use student work anonymously. Of those, 439 students returned the forms with parent signatures granting us access to their work. A copy of the permission form can be found in Appendix A. The numbers below represent the number of students who completed pre- and post-assessments and turned in signed parent permission sheets for each of the participating classes:

- Miller (BMS) taught 3 classes with a total of 70 students.

- Wilson (BMS) taught 6 classes with a total of 109 students.

- Brown (CMS) taught 6 classes with a total of 110 students.

- Davis (CMS) taught 5 classes with a total of 91 students.

Together BMS and CMS represented 20 classes for a total of 380 students. See pages $42-44$ for an explanation of the final number of students used in the analysis.

\section{Treatment}

I worked closely with my program advisor and a fellow graduate student to develop the Watershed and Engineering Design Unit curriculum evaluated in this study. Leading the team was our advisor and director of our graduate program, 
Stephanie Wagner. She coordinated efforts between organizations and worked closely with graduate students Riley Meinershagen, Lecia Schall, and me. With Professor Wagner's guidance, Riley Meinershagen began work on the curriculum and assessment the previous school year, 2011-2012, laying some of the groundwork, and later evaluated student work samples and conducted teacher interviews - work that fell outside the scope of my evaluation (Meinershagen, 2014). The year following the development of the WEDU, 2013-2014, Lecia Schall continued the study, looking specifically at student motivation and the relevance of using a STEM format in a place-based setting (Schall, 2015).

Given its place-based nature, the WEDU curriculum was written with the state's environmental literacy plan in mind and correlates strongly with the first environmental literacy strand: "Understand the physical and biological world, and our interdependent relationship with it" (Oregon Environmental Literacy Task Force, 2010). Created to align with several key components of the then-current as well as future state and federal science requirements, the WEDU curriculum incorporated the existing sixth grade state science content standards and engineering design work sample requirements, the new science standards and performance expectations from the Next Generation Science Standards, or NGSS (NGSS Lead States, 2013), and the engineering design process (chapter 8), engineering design practices (chapter 3), crosscutting concepts (chapter 4), and primary disciplinary core ideas (chapters 7 and 8) outlined in the NRC's framework (National Research Council, 2012). These alignments are further 
illustrated in Appendix B. While some of the teachers had incorporated engineering design earlier in the year, for many of the students, this was their first encounter with engineering design.

The treatment consisted of 24 lessons that introduced the concept of watersheds and how they function; the impact impervious surfaces on the students' campuses have on the local watershed(s); and incorporated engineering design to create, evaluate, and redesign place-based solutions to mitigate the effects of existing impervious surfaces. Although we originally intended the unit to take four and a half weeks, modifications I made while writing it resulted in a curriculum that is more likely to take five to six weeks to complete. 
Table 1: Progression of Lessons by Objective in the Watershed Engineering Design Unit Curriculum

Lessons 1 and 24 were the pre- and post-assessments, respectively, and are not included in this table. Some lessons address two objectives and therefore span two columns accordingly.

\begin{tabular}{|c|c|c|}
\hline $\begin{array}{l}\text { Objective 1: } \\
\text { Explain what a } \\
\text { watershed is and } \\
\text { how it functions }\end{array}$ & $\begin{array}{l}\text { Objective 2: } \\
\text { Describe impervious } \\
\text { surfaces and connect } \\
\text { their impact to the } \\
\text { watershed }\end{array}$ & $\begin{array}{l}\text { Objective } 3 \text { : } \\
\text { Perform the engineering design process }\end{array}$ \\
\hline \multicolumn{3}{|l|}{$\begin{array}{l}\text { 2. Watersheds and } \\
\text { the Water Cycle }\end{array}$} \\
\hline \multicolumn{3}{|l|}{$\begin{array}{l}\text { 3. Infiltration } \\
\text { Investigation }\end{array}$} \\
\hline \multicolumn{3}{|c|}{ 4. Runoff and Impervious Surfaces } \\
\hline & 5. Campus Calculations & \\
\hline & \multicolumn{2}{|c|}{ 6. Establish and Define the Problem } \\
\hline & & 7. Introduce the Engineering Design Process \\
\hline & \multicolumn{2}{|c|}{ 8. Choose Criteria and Constraints } \\
\hline & \multicolumn{2}{|c|}{$\begin{array}{l}\text { 9. Work sample: complete Identifying and Defining a Problem to Be } \\
\text { Solved (part 1) }\end{array}$} \\
\hline & & 10. Engineering Design Teams \\
\hline & & 11. Tools for Collecting Data on Site \\
\hline & \multicolumn{2}{|l|}{ 12. Select Sites } \\
\hline & & 13. Introduce the Pugh Chart \\
\hline & \multicolumn{2}{|c|}{ 14. Introduce Stormwater Manual Descriptions of Common Solutions } \\
\hline & & 15. Create a Detailed Design \\
\hline & & $\begin{array}{l}\text { 16. Work Sample: complete Generating } \\
\text { Possible Solutions (part 2) }\end{array}$ \\
\hline & & 17. Create Data from the Design \\
\hline & & 18. Evaluate the Detailed Design \\
\hline & & $\begin{array}{l}\text { 19. Work Sample: complete Testing } \\
\text { Solution(s) and Collecting Data (part } 3 \text { ) }\end{array}$ \\
\hline & & 20. Hold a Design Charrette \\
\hline & & 21. Make Improvements to the Design \\
\hline & & $\begin{array}{l}\text { 22. Work Sample: complete Analyzing and } \\
\text { Interpreting Results (part } 4 \text { ) }\end{array}$ \\
\hline & & 23. Revise and Edit Work Samples \\
\hline
\end{tabular}




\section{Table 2: Lesson Summaries}

Lesson titles are underlined. The lessons ranged in anticipated length from less than half of a 48minute class period to three full class periods.

\begin{tabular}{|c|c|}
\hline 1. & $\begin{array}{l}\text { Pre-assessment: Students take an 18-question multiple-choice pre-assessment to inform } \\
\text { instruction, and afterward the teacher leads a brief discussion to get an idea of what } \\
\text { students may already know or believe they know about watersheds and/or the engineering } \\
\text { design process. }\end{array}$ \\
\hline 2. & $\begin{array}{l}\text { Watersheds and the Water Cycle: Students are introduced to or refreshed on the } \\
\text { watershed concept, create and use simple watershed models, and begin to understand } \\
\text { how a watershed functions as part of the water cycle and greater geographical landscape. }\end{array}$ \\
\hline 3. & $\begin{array}{l}\text { Infiltration Investigation: Students learn about the gravity-driven process of infiltration, head } \\
\text { outdoors to observe an infiltration pit demonstration, learn about groundwater recharge and } \\
\text { the movement of water underground and into surface water. }\end{array}$ \\
\hline 4. & $\begin{array}{l}\text { Runoff and Impervious Surfaces: Students learn about the paths precipitation may take if it } \\
\text { does not infiltrate and how impervious surfaces play a part; take a tour of campus to note } \\
\text { the various impervious surfaces, downspouts, and storm drains; and watch an video } \\
\text { illustrating both how impervious surfaces impact water quality and the benefits of filtering } \\
\text { water through natural systems. }\end{array}$ \\
\hline 5. & $\begin{array}{l}\text { Campus Calculations: Students do calculations on their own campuses to identify how } \\
\text { much their campus contributes to the problem of untreated storm water rushing out of pipes } \\
\text { into nearby drainage ditches and creeks. }\end{array}$ \\
\hline 6. & $\begin{array}{l}\text { Establish and Define the Problem: Students summarize what they have learned in previous } \\
\text { lessons by articulating the environmental problems brought on by stormwater and define it } \\
\text { as a problem, setting the stage for the engineering design work. }\end{array}$ \\
\hline 7. & $\begin{array}{l}\text { Introduce the Engineering Design Process: Students replace their previous conceptions of } \\
\text { engineering and technology with accurate definitions and examples, are introduced to the } \\
\text { Engineering Design Process, and are empowered in learning that they have likely used } \\
\text { engineering processes before without realizing it. }\end{array}$ \\
\hline 8. & $\begin{array}{l}\text { Choose Criteria and Constraints: Students revisit the challenge problem and discuss and } \\
\text { decide on, with the help a part of the student version of the city stormwater manual, criteria } \\
\text { and constraints that define and delimit the engineering problem: reducing the water that } \\
\text { leaves campus as stormwater to lessen the impact of impervious surfaces on the } \\
\text { watershed. }\end{array}$ \\
\hline 9. & $\begin{array}{l}\text { Work sample: complete Identifying and Defining a Problem to Be Solved (part 1): Students } \\
\text { complete the first of four sections of the work sample (similar to a formal lab write-up): } \\
\text { Identifying and Defining a Problem to Be Solved. }\end{array}$ \\
\hline 10. & $\begin{array}{l}\text { Engineering Design Teams: Students establish Engineering Design Teams and } \\
\text { expectations of cooperation and participation. }\end{array}$ \\
\hline 11. & $\begin{array}{l}\text { Tools for Collecting Data on Site: Students learn how to collect appropriate data using } \\
\text { metric units, interpret and create aerial images, and accurately measure and represent } \\
\text { their campus plots on graph paper. }\end{array}$ \\
\hline 12. & $\begin{array}{l}\text { Select Sites: Student teams visit their assigned campus plots (most plots contain an area of } \\
\text { impervious surface from which to reroute runoff and a large pervious surface), select } \\
\text { possible solution sites within their plots, take notes, and make sketches on the provided } \\
\text { aerial maps with grid overlays. }\end{array}$ \\
\hline
\end{tabular}


Table 2: Lesson Summaries, continued

13. Introduce the Pugh Chart: Students independently generate ideas for solutions specific to their sites, collaborate using a Pugh chart to evaluate solution ideas against the established criteria and constraints, and decide upon a design direction to develop further.

14. Introduce Stormwater Manual Descriptions of Common Solutions: Students are introduced to seven common stormwater solutions through the Student Stormwater Manual (an adaptation of the local stormwater manual) to help them further develop, with additional design-specific criteria and constraints, their own ideas.

15. Create a Detailed Design: Student teams sketch scale detailed designs mindful of the criteria and constraints of the challenge problem, additional criteria and constraints specific to their specific type of stormwater solution, and the specific needs and parameters of their site within their plot.

16. Work Sample: complete Generating Possible Solutions (part 2): Students complete the second of four sections of the work sample: Generating Possible Solutions.

17. Create Data from the Design: Student teams gather surface area and depth measurements from their detailed designs and enter them into an online calculator that quickly and accurately provides them with data with which to evaluate their solution designs by how much stormwater they can process in relation to the runoff volume generated by their impervious surface during a 24 hour storm event.

18. Evaluate the Detailed Design: Student teams use data generated by the online calculator and modified Pugh charts to evaluate their designs and identify areas for improvement, make changes to the detailed design accordingly, and prepare to share their solution design with their classes.

19. Work Sample: complete Testing Solution(s) and Collecting Data (part 3): Students complete the third of four sections of the work sample: Testing Solution(s) and Collecting Data.

20. Hold a Design Charrette: Student teams take turns presenting their solution design sketches, measurements, data, and modified Pugh charts to their classmates while students in the audience participate by providing productive feedback to the presenters regarding specific criteria and constraints.

21. Make Improvements to the Design: Student teams collaboratively review positive feedback and constructive criticism from peers to discuss and identify possible areas for final improvements to their designs, make (or do not make) adjustments accordingly, and justify their rationale in writing.

22. Work Sample: complete Analyzing and Interpreting Results (part 4): Students complete the fourth of four sections of the work sample: Analyzing and Interpreting Results.

23. Revise and Edit Work Samples: Students use a self-assessment checklist to take a critical look at and score their work samples using the language from the state scoring guide first alone, then in pairs or triads of peers from outside the Engineering Design Teams, and make improvements as needed.

24. Post-Assessment: Students retake the 18-question multiple-choice pre-assessment to demonstrate their fluency with the three objectives: "Explain what a watershed is and how it functions" (questions 1-9); "Describe impervious surfaces and connect their impact to the watershed" (10-12, 18); and "Perform the engineering design process" (13-17). 


\section{Instrument}

For my evaluation I have focused on analyzing the data provided by the pre- and post-assessments, which students took before the first lesson and at the conclusion of the unit. Also important to the student learning were the lab packets or lab notebooks students used to take notes, record observations, make calculations, practice skills, and create and refer to resources throughout the unit. These tools, student engineering design work samples, and semi-structured student interviews were evaluated and analyzed by my colleague Riley Meinershagen as a part of his thesis research.

Pre-post assessment. The watershed and engineering design unit pre- and post-assessment included 18 five-option multiple-choice questions. In keeping with the STEM conceptual knowledge construct as described by the STEM Common Measurement System (Saxton et al., 2014), several of the questions assess conceptual knowledge. After revising and editing several drafts of the assessment with my advisor and colleagues, I sent the assessment to the participating sixth-grade teachers who checked it for accuracy and suitability for their audience. They confirmed their approval. A complete copy of the assessment can be found in Appendix C.

Objective 1 - Explain what a watershed is and how it functions, is addressed in questions $1-9$. Included were multiple-choice questions about:

- Location, shape, and health of watersheds 
- Forces moving water within a watershed

- Groundwater and stream recharge

- Flow of water within a watershed

Objective 2 - Describe impervious surfaces and connect their impact to the watershed, is addressed in questions $10-12$ and 18. Included were multiple-choice questions about:

- Identification and impact of impervious surfaces

- Rainfall on impervious surfaces

- Finding the area of an impervious surface

Objective 3 - Perform the engineering design process, is addressed in questions $13-15$ and 17 . Included were multiple-choice questions about:

- Identifying technology

- Interpreting an engineering design Pugh chart

The four multiple-choice questions aligned to Objective 3, which dealt with the engineering design process, assess only a fraction of the engineering design work students did in lessons 6-23 (see Table 2). This is because the engineering design process does not lend itself to multiple-choice assessment. Students demonstrated their engineering design knowledge and skill through work samples they created throughout the unit. My colleague, Riley Meinershagen, evaluated some of these work samples as a part of his project. 


\section{Procedure}

The classroom teachers administered the pre-assessment in all 20 classrooms on Monday, May 6, 2013, and began teaching lessons the next day. Lessons took place both in the classrooms at Basin and Catchment Middle Schools and on the grounds around the schools as students engaged in engineering design. The post-assessments were administered June 5 and 6 at Basin Middles School and June 10-12 at Catchment Middle School after only lesson 15 or 16 of 24 . Due to circumstances I will address in the discussion, the school year ran out before the curriculum was completed. Students were therefore unable to evaluate and improve their engineering design solutions as planned. Students recorded their answers to the questions by marking on Scantron-style answer sheets. These sheets were coded to reflect the teacher, class period, and student (by number), and crosschecked against the forms signed by parents granting us access to their students' data. The teachers ran the answer keys through scoring machines and I checked them by hand. I then entered the data into Microsoft Excel spreadsheets. For each student I recorded:

- A distinct letter and number combination to reflect the teacher, the class period, and the number assigned in place of the student's name

○ Example: M4.26 stands for student number 26 in Ms. Miller's fourth period class.

- Codes were given to keep data organized, preserve anonymity, and prevent possible bias 
- Verification of a signed permission slip

- Whether or not each question was answered correctly on the preassessment

- Whether or not each question was answered correctly on the postassessment

- The specific answer chosen for all questions on the post-assessment

- The difference between the pre- and post-assessment scores

- The assessment questions that the student answered correctly on the preassessment but incorrectly on the post-assessment, if any 


\section{Results}

This evaluation looked at the impact of a watershed and engineering design curriculum on 266 suburban sixth-graders in 14 classrooms during the 2012-2013 school year. This section provides the results from comparison of the students' pre- and post-intervention scores on a multiple-choice knowledge and skills assessment. The Watershed Engineering Design Unit (WEDU) engaged students in three learning objectives, which are also the subject of this evaluation: (1) watershed function; (2) the impact of impervious surfaces; and (3) the engineering design process. The assessment data was made up of 17 questions, which were keyed to the learning objectives. Objective 1 aligned with nine questions (questions $1-9$ ) while Objectives 2 (questions 10,11, 12, and 18) and 3 (questions 13, 14, 15, and 17) each aligned with four questions. Questions were sequenced in the order of the objectives with the exception of question 18, which was aligned to Objective 2 but was placed at the end of the assessment because it was on a page students could mark up rather than part of the assessment packet that was meant to be returned to the teacher. Originally there were 18 questions in the assessment, however question 16 was discarded due to a typo that made it unusable. Students recorded their answers to the assessment questions on Scantron-style test sheets that I transferred into Microsoft Excel workbooks for analysis.

Working with Excel and the add-in PHStat2 I ran four two-sampled, lowertail, paired $t$-tests with unsummarized data. These tests compared student 
performance on the pre-assessment to performance on the post-assessment for the individual learning objectives and the assessment as a whole. The level of significance was set at $p<0.05$ and the hypothesized mean difference at 0 . Therefore, a result with a $p$ value of less than 0.05 would indicate a rejection of the null hypothesis that there was no gain in student knowledge and skill and conversely indicating evidence that there was a statistically significant gain in student knowledge and skill between the pre- and post-assessments as demonstrated by the assessment data.

The top half of Table 3 shows the averaged scores per objective for the pre- and post-assessment as well as the gain between them. The bottom half of the table shows the lower-tailed, paired sample statistics delineated by learning objective as well as summarized in the last row. The first row of the statistics represents Objective 1: "Explain what a watershed is and how it functions." With a standard deviation of 1.9585 points and a $p$-value $<0.0001$, there is strong evidence to reject the null hypothesis and conclude that it is highly likely that students made gains in understanding watersheds and watershed function between the pre- and post-assessments. The nine questions in this section asked students about the location and shape of watersheds, how water moves within a watershed, what groundwater is, and how human development has impacted the health of watersheds. Students were asked questions about the flow of water within their local watershed (with and without the aid of maps) as well as the source of water in creeks during dry spells. 
Table 3: Pre- and Post-Assessment Analysis by Objective

The percentages in this table represent the average scores, per objective, on the pre- and postassessments as well as the gain between the two assessments; $n=266$ students

\begin{tabular}{|l|c|c|c|}
\hline \multicolumn{1}{|c|}{ Objective Tested } & \multicolumn{2}{|c|}{ Average Scores } \\
\hline $\begin{array}{l}\text { Objective 1: Explain what a } \\
\text { watershed is and how it functions } \\
\text { (Questions 1 - 9) }\end{array}$ & Pre-Assessment & Post-Assessment & $\begin{array}{c}\text { Gain from Pre- to } \\
\text { Post-assessment }\end{array}$ \\
\hline $\begin{array}{l}\text { Objective 2: Describe impervious } \\
\text { surfaces and connect their impact } \\
\text { to the watershed } \\
\text { (Ques. 10, 11, 12, 18) }\end{array}$ & $51 \%$ & $62 \%$ & $19 \%$ \\
\hline $\begin{array}{l}\text { Objective 3: Perform the } \\
\text { engineering design process } \\
\text { (Ques. 13, 14, 15, 17) }\end{array}$ & $45 \%$ & $76 \%$ & $25 \%$ \\
\hline All three objectives combined & $46 \%$ & $72 \%$ & $26 \%$ \\
\hline
\end{tabular}

For each test $n=266$, the hypothesized mean difference between scores on the preassessment and post-assessment was 0 , and the level of significance was 0.05

\begin{tabular}{|l|c|c|c|c|c|}
\hline \multicolumn{1}{|c|}{} & \multicolumn{5}{|c|}{ Lower-Tailed Paired Sample Statistics } \\
\hline \multicolumn{1}{|c|}{ Objective Tested } & $\begin{array}{c}\text { Standard } \\
\text { Deviation }\end{array}$ & $\begin{array}{c}t \text { Test } \\
\text { Statistic }\end{array}$ & $\begin{array}{c}\text { Lower } \\
\text { Critical } \\
\text { Value }\end{array}$ & $p$-Value & Interpretation \\
\hline $\begin{array}{l}\text { Objective 1: Explain what a } \\
\text { watershed is and how it functions } \\
\text { (Questions 1 -9) }\end{array}$ & 1.9585 & -14.4007 & -1.6506 & $<0.0001$ & $\begin{array}{c}\text { Reject the null } \\
\text { hypothesis }\end{array}$ \\
\hline $\begin{array}{l}\text { Objective 2: Describe impervious } \\
\text { surfaces and connect their impact } \\
\text { to the watershed } \\
\text { (Ques. 10, 11, 12, 18) }\end{array}$ & 1.3317 & -12.0632 & -1.6506 & $<0.0001$ & $\begin{array}{l}\text { Reject the null } \\
\text { hypothesis }\end{array}$ \\
\hline $\begin{array}{l}\text { Objective 3: Perform the } \\
\text { engineering design process } \\
\text { (Ques. 13, 14, 15, 17) }\end{array}$ & 1.2213 & -14.0571 & -1.6506 & $<0.0001$ & $\begin{array}{l}\text { Reject the null } \\
\text { hypothesis }\end{array}$ \\
\hline All three objectives combined & 2.9725 & -20.6680 & -1.6506 & $<0.0001$ & $\begin{array}{l}\text { Reject the null } \\
\text { hypothesis }\end{array}$ \\
\hline
\end{tabular}

Objective 2: "Describe impervious surfaces and connect their impact to the watershed," is shown in the second row. With a standard deviation of 1.3317 
points and a $p$-value $<0.0001$, there is strong evidence to reject the null hypothesis and conclude that it is highly likely that students made gains in understanding impervious surfaces and the impact those surfaces have on watersheds between the pre- and post-assessments. There were four questions pertaining to this learning objective and they asked students about where rain goes after landing on a street; asked them to identify impervious surfaces and the environmental impacts of impervious surfaces; and asked them to figure out the area of a fictional impervious surface using an areal map.

The third row represents Objective 3: "Perform the engineering design process." With a standard deviation of 1.2213 points and a $p$-value $<0.0001$, there is strong evidence to reject the null hypothesis and again conclude that it is highly likely that students made gains in engineering design skills between the pre- and post-assessments. The four questions relating to the third objective asked students to identify examples of technology as well as interpret and use a Pugh chart as part of an engineering design scenario.

Not surprisingly, the combined results of these three objectives also show statistical significance, as displayed in the final row of Table 3. With a standard deviation of 2.9725 points and a $p$-value $<0.0001$, there is again strong evidence to reject the null hypothesis and conclude that it is highly likely that students made gains in understanding and skills relating to watersheds, impervious surfaces, and the engineering design process between the pre- and postassessments. 
Table 4: Pre- and Post-Assessment Analysis by Individual Question

This table compares aggregate student performance by individual assessment question. It shows how many students answered each question correctly on the pre-assessment and on the identical post-assessment. Also shown are the gains in correct answers from the pre- to the post-assessment. All figures are given both in terms of how many of the 266 students answered correctly and as percentages. The lightly shaded questions have between $50 \%$ and $74 \%$ answering correctly whereas the darkly shaded questions have less than $50 \%$.

\begin{tabular}{|c|c|c|c|c|c|c|c|}
\hline \multirow{2}{*}{ 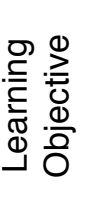 } & \multirow{2}{*}{ 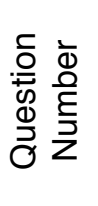 } & \multicolumn{2}{|c|}{$\begin{array}{l}\text { Correct Answers on } \\
\text { Pre-Assessment }\end{array}$} & \multicolumn{2}{|c|}{$\begin{array}{l}\text { Correct Answers on } \\
\text { Post-Assessment }\end{array}$} & \multicolumn{2}{|c|}{$\begin{array}{l}\text { Gain in Correct } \\
\text { Answers from } \\
\text { Pre to Post }\end{array}$} \\
\hline & & Students & Percent & Students & Percent & Students & Percent \\
\hline 1 & 1 & 137 & $52 \%$ & 208 & $78 \%$ & 71 & $27 \%$ \\
\hline 1 & 2 & 42 & $16 \%$ & 112 & $42 \%$ & 70 & $26 \%$ \\
\hline 1 & 3 & 41 & $15 \%$ & 73 & $27 \%$ & 32 & $12 \%$ \\
\hline 1 & 4 & 168 & $63 \%$ & 205 & $77 \%$ & 37 & $14 \%$ \\
\hline 1 & 5 & 175 & $66 \%$ & 236 & $89 \%$ & 61 & $23 \%$ \\
\hline 1 & 6 & 209 & $79 \%$ & 240 & $90 \%$ & 31 & $12 \%$ \\
\hline 1 & 7 & 60 & $23 \%$ & 73 & $27 \%$ & 13 & $5 \%$ \\
\hline 1 & 8 & 116 & $44 \%$ & 168 & $63 \%$ & 52 & $20 \%$ \\
\hline 1 & 9 & 84 & $32 \%$ & 175 & $66 \%$ & 91 & $34 \%$ \\
\hline 2 & 10 & 203 & $76 \%$ & 238 & $89 \%$ & 35 & $13 \%$ \\
\hline 2 & 11 & 151 & $57 \%$ & 252 & $95 \%$ & 101 & $38 \%$ \\
\hline 2 & 12 & 67 & $25 \%$ & 161 & $61 \%$ & 94 & $35 \%$ \\
\hline 3 & 13 & 127 & $48 \%$ & 223 & $84 \%$ & 96 & $36 \%$ \\
\hline 3 & 14 & 132 & $50 \%$ & 202 & $76 \%$ & 70 & $26 \%$ \\
\hline 3 & 15 & 115 & $43 \%$ & 164 & $62 \%$ & 49 & $18 \%$ \\
\hline 3 & 17 & 107 & $40 \%$ & 173 & $65 \%$ & 66 & $25 \%$ \\
\hline 2 & 18 & 123 & $46 \%$ & 154 & $58 \%$ & 31 & $12 \%$ \\
\hline
\end{tabular}

Recall that question 16 was not included because it contained a typo that made it unusable.

Table 4 describes each question on the assessment individually, showing how many students answered the question correctly on the pre-assessment, how many answered correctly on the post-assessment, and the total gain 
demonstrated as difference between the two. In all cases there was gain demonstrated, though some questions showed much greater gains than others. Results are reported in terms of the number of students answering questions correctly as well as the percentage of students out of the total 266 students in the data set (note that more data will be introduced in the discussion and recommendation section when I discuss which options students selected when they chose incorrect options). Recall that the questions in the pre- and postassessment were keyed to particular learning objectives so that we could analyze different portions of the curriculum independently of one another and as a whole. The statistical analysis of those objectives is detailed in Table 3. The statistically significant findings and the strong evidence to reject the null hypothesis lead to the conclusion that students made gains across all three learning objectives. 


\section{Limitations and Delimitations}

This section looks at the limits and delimitations of this project. There were several delimitations that constrained the work I did as well as the generalizability of my findings. The most important delimitation was the multiple-choice structure of the assessment. Using this type of question was necessary given the time constraints and quantity of students participating. The limitations of this type of question, however, are significant. Multiple-choice items limit student responses to those chosen by the writer, thereby limiting the information the assessment can generate, and possibly accidentally reinforcing misconceptions by listing them as plausible options from which to answer the question. With only five options for each question (A through E on the Scantron-style answer sheet)barring leaving the question blank or filling in more than one bubble-students have a $20 \%$ chance of getting each question correct by merely guessing. Could some of this guessing have inflated the data by combining true gains in learning with guesswork? Were there students who thoroughly understood the material but struggle with multiple-choice format and, as a result, underperformed on the assessment? Perhaps some of these concerns can be mitigated in future iterations of the assessment.

In addition to looking at delimitations, I also want to discuss the limitations of the study. The first limitation faced was that of the population participating in the curriculum, which was comprised of the entire sixth-grade class of one affluent, predominantly white, suburban school district. The population is not 
necessarily representative of the Pacific Northwest region, let alone the country, and there was no comparison group against which to measure our findings. Participating in the curriculum were all of the district's 514 sixth-grade students in 20 pre-established classrooms. Of those students, we had access to the work of 439 students who had returned the appropriate permission form. I was only able to work with data from students who had completed both the pre- and postassessments, and removing students with only one or the other brought my sample size down to 380 students.

A second limitation occurred when, recording the post-assessment data, I noticed that none of the 23 students in Mr. Wilson's fourth period class answered question 18. I do not know exactly why this happened but I suspect Mr. Wilson ran out of test sheets for this question as this was the one question students were allowed to write on before recording their answer, unlike the rest of the questions in the assessment. For this reason I had to exclude this class from the sample, bringing the sample size down to 357 students in 19 classrooms.

Another significant limitation was the result of a testing irregularity by one teacher. As mentioned, the four teachers piloting the unit were given assessment packets that could be reused by each class as students recorded their multiplechoice answers on Scantron-style answer sheets. What I did not anticipate was that Mr. Davis (or his substitute teacher) had his five classes record their answers the pre-assessment on one side of a two-sided Scantron-style answer sheet, and, weeks later, their answers to the post-assessment on the other. At 
first this seemed like a convenient feature that made collating data easier for me. But then I realized that these students were given an unfair advantage. Because they were taking the same assessment twice, they were able to look to the preassessment side, which had been scored, and see how they had answered each question the first time. If they had guessed correctly, all they had to do was copy that answer over to the post-assessment. They also had a small advantage on questions they had missed the first time because now they knew one of the incorrect options and had only four remaining options to select from.

Not knowing if this really posed an advantage for Mr. Davis's students as compared to the other sixth-grade students, I went back and counted up the instances where students had gotten a problem incorrect on the postassessment after getting it correct on the pre-assessment. The average number of questions like this was 0.18 for students in Davis' classes, whereas the average was 1.39 questions for all other students. Another way to look at it was that only $12 \%$ of Davis' students missed one or more questions on the post- that they had answered correctly on the pre-assessment. Of the other sixth-graders, that percentage was $73 \%$. In other words, students not in Mr. Davis' class were six times as likely to miss a problem on the post-assessment that they had answered correctly on the pre-assessment. Those figures were unusual enough for me to conclude that Davis' students had an unfair advantage as compared to their peers and that their assessments should be withheld from the data set. For this reason the number of students included in the evaluation was further 
reduced from 357 to 266 and the number of classrooms from 19 to 14 . It was frustrating to work with only data from only $52 \%$ of the 514 students that participated in the unit.

The pre- and post-assessment, as written, contained 18 questions. In my rush to print up the assessment packets and get them to the teachers for preassessments, I inadvertently created another limitation. I failed to notice that somehow I was working with a previous draft of the file that contained a typo in question 16, one of the engineering design questions. Had it been a spelling typo or some other small problem such as a miswording, the question may have been salvageable, but unfortunately the problem was with the correct option, leaving the question with no correct option to select. Without time to reprint the page, students were instructed to skip it and as a result there was one fewer question for Objective 3: "perform the engineering design process" and for the assessment as a whole.

Despite the problems that limited the number of assessments I had to work with or the error that reduced the number of questions on the assessment, the limitation with likely the largest impact was that the 2012-2013 school year ran out before the unit was completed. In order to give the post-assessment in time, the teachers reported ending the unit after lesson 15 to lesson 16, leaving seven or eight lessons untaught. As explained further in the discussion section, the lessons students skipped are primarily engineering design focused (Objective 3), which means students did not get a chance to do the following: complete a 
detailed design; gather data from that design; evaluate it; collaborate with peers; improve the design; analyze, interpret, and communicate results. Missing out on a third of the unit likely left many students with an incomplete understanding of the engineering design process, which more than likely affected their ability to demonstrate learning gains on the post-assessment. 


\section{Discussion and Recommendations}

At the forefront of my work on this project was the goal of creating a useful curriculum that would teach students about watersheds and the impacts of impervious surfaces in urban environments on watersheds, and help students use the engineering design process to create solutions to mitigate the effects of impervious surfaces on watersheds. The goal of this research was to evaluate said curriculum using pre- and post-assessment data. In the previous results section I reported the findings and in this section I will discuss their significance and look at some of the more interesting data that have implications for future iterations of the curriculum and assessment tool, and watershed and engineering design education as a whole.

The research question in this project looked at the impacts of the Watershed Engineering Design Unit (WEDU) curriculum on 266 urban sixthgrade students related to three specific learning objectives: (1) watershed function, (2) the impacts of impervious surfaces, and (3) the engineering design process. With $t$-tests comparing pre- and post-assessment student data resulting in $p$-values lower than 0.0001 for each of the three objectives, the result is a strong rejection of the null hypothesis of no student learning gain for each objective taken individually as well as in the aggregate. This means that the goals of our research were met as students made statistically significant gains in all three learning objectives. 
Within the Results section, Table 3 shows us a breakdown of student gains in student knowledge and skills. On the pre-assessment, the students answered an average of $45 \%$ of the questions correctly. On the post-assessment, this same number rose to $68 \%$. The gain of more than $22 \%$ made for statistically significant results. Looking more specifically within the assessment tool, Table 4 points us toward areas of specific strength and weakness. Focusing on the strengths - those questions answered correctly by $75 \%$ or more of the students gives us a chance to reflect on the what the data suggests may be the most successful aspects of the curriculum which are likely to stay similar in future iterations of the unit. Taking note of the weaknesses - those questions answer correctly by fewer than $75 \%$ of the students - allows us an opportunity to reexamine the curriculum and the assessment tool itself with an eye for improving it in the years to come. Could these lower-performing questions indicate persisting misconceptions at work in the minds of students? Could they point to areas of weakness within the curriculum or flaws in the assessment tool? Delving into these questions lays the groundwork for making recommendations for improvements to the curriculum and the assessment.

In order to learn more about the incorrect answers students gave, I drilled into this data by creating an Excel workbook reflecting the spread of incorrect answers so that I could see the distribution of incorrect responses. Doing so allowed me to total up all of the times each option was selected. This information is provided within figures $1-7$ along with the text of the questions as they 
appeared on the pre- and post-assessment (though without some accompanying images and with some identifying place names concealed; the full assessment can be found in Appendix C). The small tables to the right of each question show the frequency with which each option, $A, B, C, D$, or $E$ (options are referred to in the table as Mark) was selected for that question on the post-assessment, both as a number of students out of 266 (\#) and a percentage (\%). The "None/Two" row is included to reflect questions were students either made no mark (left it blank) or made two marks on the same answer. None/Two, indicates that the number of times no mark was made, whereas None/Two indicates the frequency of two marks. Both responses were recorded as incorrect answers. Correct answers are highlighted. Italicized and bolded marks indicate a distractor (incorrect answer) that was selected more frequently than the correct answer. Below the breakdown of the student post-assessment data is the gain made, from pre-assessment to post-assessment, as a result of participation in the WEDU.

Following are six subsections focusing on the strengths and areas for improvement of each of the three learning objectives of the WEDU. Within each subsection will be a figure as described above, analysis of the data from that figure, as well as ties to the literature and recommendations for future practice as applicable.

\section{Objective 1: Explain What a Watershed is and How It Functions}


The first objective looked at student understanding of watersheds and watershed functions. All together, the learning gains for this objective were statistically significant with a standard deviation of 1.9585 and a $p$-value of $<0.0001$. Of those questions, the four that I consider more successful were 1,4 , 5, and 6. Less successful were questions $2,3,7,8$, and 9.

Strengths. The first successful question I want to look more closely at is question 1 , which asks students to identify where watersheds are located. This question was developed to check for one of the misconceptions Shepardson et al. (2007) found when they analyzed the illustrations they collected from students. They found that, aside from the students misrepresenting watersheds as humanbuilt water storage containers, most students focused entirely on natural settings for their watershed illustrations, showing a lack of understanding of humans as being a part of, and effecting, watersheds. Looking at the results from our students, we found that $14 \%$ of students considered watersheds to be in cities or anywhere there are people, $7 \%$ considered watersheds to be in either wilderness areas or dry locations, and the majority, $78 \%$, recognized that watersheds are found in all of those areas. This last score is a $27 \%$ gain from the $52 \%$ of students answering correctly on the pre-assessment. These results suggest that our curriculum may have been beneficial in dispelling this common misconception.

Success with question 4 (77\% answering correctly up $14 \%$ from $63 \%$ on the pre-assessment) shows a basic understanding of groundwater. Question 6, 
Figure 1: Objective 1 Strengths

Tables show the frequency with which each option/mark, A, B, C, D, or E (Mark), was selected for that question on the post-assessment, both as a number of students out of 266 (\#) and a percentage (\%). Correct answers are highlighted. Italicized and bolded marks indicate a distractor (incorrect answer) that was selected more frequently than the correct answer.

\begin{tabular}{|c|c|c|c|}
\hline Question from the WEDU Pre- and Post-Assessment & Mark & \# & $\%$ \\
\hline \multirow{7}{*}{$\begin{array}{l}\text { 1. Watersheds are found } \\
\text { a. in cities. } \\
\text { b. anywhere there are people. } \\
\text { c. in wilderness areas. } \\
\text { d. in dry locations. } \\
\text { e. in all of the above options. }\end{array}$} & A & 10 & $4 \%$ \\
\hline & $\mathrm{B}$ & 28 & $11 \%$ \\
\hline & $\mathrm{C}$ & 16 & $6 \%$ \\
\hline & $\mathrm{D}$ & 2 & $1 \%$ \\
\hline & $E$ & 208 & $78 \%$ \\
\hline & None/Two & 2 & $1 \%$ \\
\hline & \multicolumn{2}{|c|}{ Gain from Pre } & $27 \%$ \\
\hline \multirow{7}{*}{$\begin{array}{l}\text { 4. Groundwater is } \\
\text { a. water that sits on the ground. } \\
\text { b. water that is stored on the ground. } \\
\text { c. water that is stored underground } \\
\text { d. water in streams and rivers. } \\
\text { e. all of the above options. }\end{array}$} & A & 11 & $4 \%$ \\
\hline & $\mathrm{B}$ & 17 & $6 \%$ \\
\hline & $\mathrm{C}$ & 205 & $77 \%$ \\
\hline & $\mathrm{D}$ & 11 & $4 \%$ \\
\hline & $E$ & 22 & $8 \%$ \\
\hline & None/Two & 0 & $0 \%$ \\
\hline & \multicolumn{2}{|c|}{ Gain from Pre: } & $14 \%$ \\
\hline \multirow{7}{*}{$\begin{array}{l}\text { 5. All together, human development such as houses, roads, } \\
\text { stores, and factories, has } \\
\text { a. not affected watersheds. } \\
\text { b. made watersheds healthier. } \\
\text { c. made watersheds less healthy. } \\
\text { d. created watersheds. } \\
\text { e. happened only outside of watershed areas. }\end{array}$} & $A$ & 8 & $3 \%$ \\
\hline & B & 5 & $2 \%$ \\
\hline & C & 236 & $89 \%$ \\
\hline & $\mathrm{D}$ & 16 & $6 \%$ \\
\hline & $E$ & 1 & $0 \%$ \\
\hline & None/Two & 0 & $0 \%$ \\
\hline & \multicolumn{2}{|c|}{ Gain from Pre: } & $23 \%$ \\
\hline \multirow{7}{*}{ 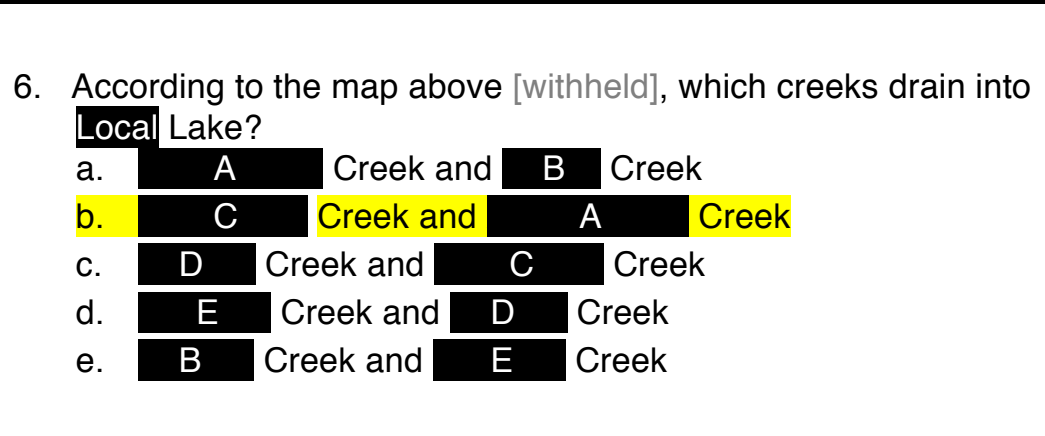 } & $A$ & 14 & $5 \%$ \\
\hline & B & 240 & $90 \%$ \\
\hline & $\mathrm{C}$ & 6 & $2 \%$ \\
\hline & $\mathrm{D}$ & 4 & $2 \%$ \\
\hline & $E$ & 2 & $1 \%$ \\
\hline & None/Two & 0 & $0 \%$ \\
\hline & \multicolumn{2}{|c|}{ Gain from Pre: } & $12 \%$ \\
\hline
\end{tabular}


which had a strong showing on the pre-assessment with $79 \%$, was up to $90 \%$ on the post-assessment, showing some understanding of the movement of surface water. Question 5 points to the negative impact of human development on watershed health. With a strong gain of $23 \%$, this question was answered correctly by $89 \%$ of students on the post-assessment.

Areas for improvement. Three questions $-2,3$, and $7-$ stood out in terms of poor scores. Question 2 asks students to identify which of five images "best illustrates a watershed." Although the percentage of students answering correctly (with D, the bowl), rose from $16 \%$ of students on the pre-assessment to $42 \%$ on the post-assessment, a gain of more than $26 \%$, that still leaves the majority of students answering the question incorrectly. Looking to the distribution of the four incorrect options we see that nearly half of the students answering incorrectly $(27 \%)$ chose $E$, the water tower image. A water tower seems like an almost literal interpretation of the word "watershed" and shows that over a quarter of the students did not fully understand watersheds to be natural processes and still cling to the idea that watersheds are man-made. Results for this question are consistent with Shepardson et al.'s 2007 findings which showed that $67 \%$ of the suburban fourth- through twelfth-graders they surveyed thought of watersheds as human-built water storage containers, largely sheds and towers.

As with question 2, the percentage of students answering question 3 correctly on the pre-assessment (15\%) is lower than would have been anticipated if students had merely selected at random (with five-option multiple-choice 
Figure 2: Objective 1 Areas for Improvement

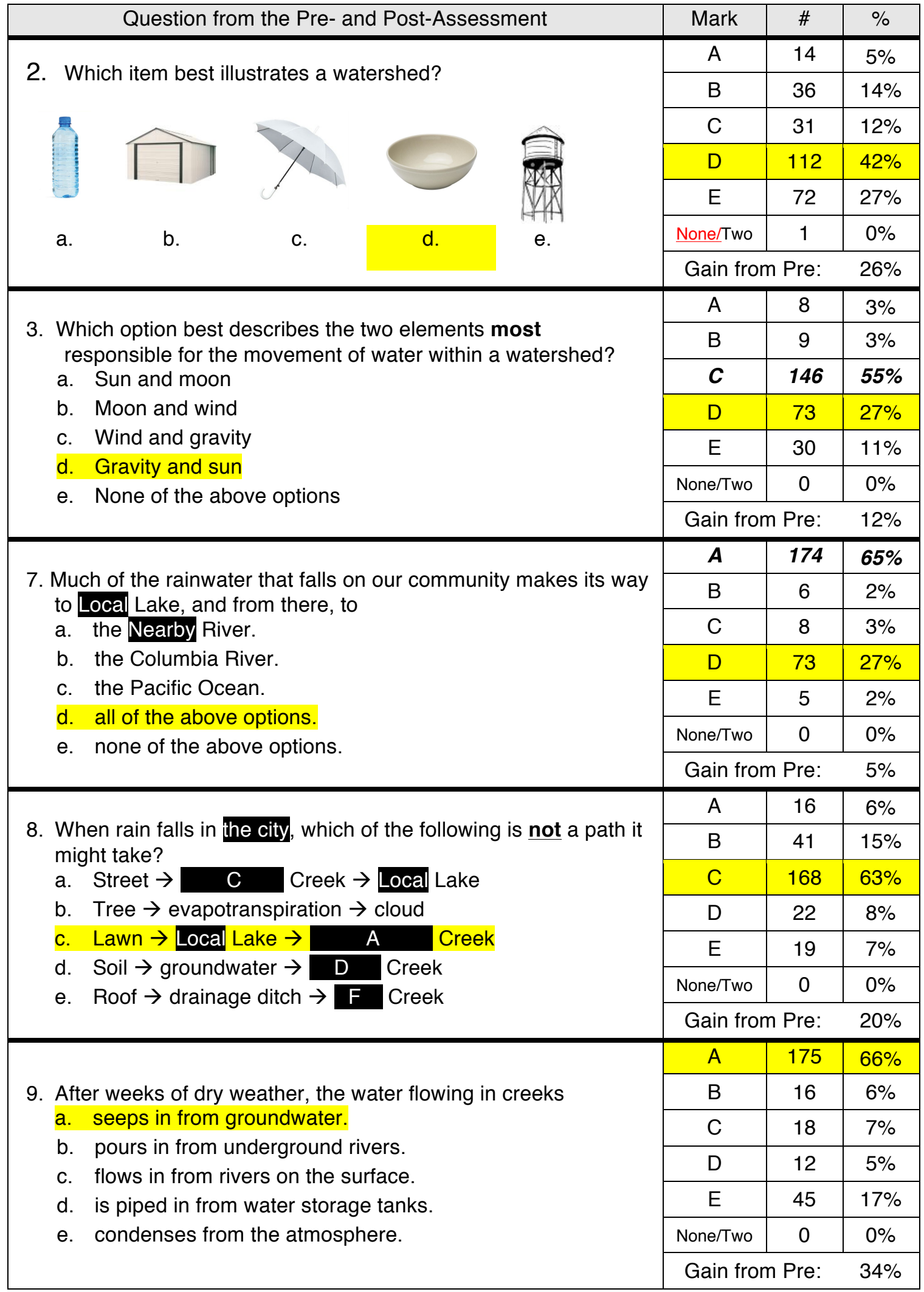


questions, there is a one in five, or $20 \%$ chance, of answering a question correctly at random). With the post-assessment showing just over a quarter of students answering question 3 correctly, the results were still quite low (despite a gain of $12 \%$ ) and tied for lowest performing question on the post-assessment. Only $27 \%$ of students answered question 3 , "Which option best describes the two elements most responsible for the movement of water within a watershed?" correctly with the answer "D, gravity and the sun." The majority of students (55\%) responded instead with "C, wind and gravity." To their credit, wind does play a part in moving clouds and precipitation. The sun's role as the energy source that powers evaporation could certainly be made clearer in the curriculum and, ideally, in earlier years of science education when students are first introduced to the water cycle.

Question 7 surprised me in that the small percentage of students $(27 \%)$ answering this question correctly on the post-assessment was up less than $5 \%$ from those who answered it correctly on the pre-assessment (23\%). Question 7 is written such that there were multiple partially correct options, one completely correct option, and one completely incorrect option. The intention behind this question was to get at both where water goes when it leaves the local community, as well as the nested nature of watersheds. There were a handful of students that picked the 'none of the above' option which was the only answer that contained no correct information. Answers (B) The Columbia River and (C) the Pacific Ocean, both of which are partially correct, also attracted a handful of 
students. The correct answer is $D$ because the water flows from the [Local] Lake to the [Nearby] River and from there to the Columbia River and out to the Pacific Ocean. Unfortunately the bulk of the students, $65 \%$, answered [Local] River (A). That answer is partially correct, of course, as that is the first destination for water leaving the lake. I believe there are three likely explanations for the answers students gave: either students did not understand that from the [Local] River the water continues to flow into the Columbia River and then out to the Pacific Ocean, or they did not understand that the water could have more than one destination, or, perhaps most likely, they stopped reading options after coming across the first plausible answer.

The complete picture created by Objective 1 is somewhat conflicted. From question 1 we see that students know where watersheds are, but question 2 tells us they are confused about what they look like, while question 3 tells us they are unclear about the forces that move water around a watershed. To summarize the questions in this section, the students came away understanding what groundwater is (question 4) and that the overall human impact on watersheds has been to make them less healthy (question 5). With the aid of a map they demonstrated an understanding of which creeks drain into their Local Lake (question 6) but, as we saw with question 7 , failed to show an understanding of the nested nature of watersheds and the complete path of water leaving their community. When provided a list of choices, a small majority of students were able to recognize which options were viable paths for rainfall to take (such as 
street $\rightarrow$ creek $\rightarrow$ lake), but nearly $40 \%$ of students did not answer this question correctly, many of them going for distractor option " $\mathrm{B}$, tree $\rightarrow$ evapotranspiration $\rightarrow$ cloud" (question 8). The same uncertainty is evident in identifying the origin of water flowing in creeks during dry weather (question 9), which was correctly identified as "A, seep[ing] in from groundwater," by $66 \%$ of the students. Curiously, option "E, condenses from the atmosphere"-a distractor not based on a known misconception - was the most commonly chosen incorrect answer with $17 \%$ of students selecting it.

What explains these discrepancies? It seems to me that students performed better on the more concrete, tangible questions and struggled more frequently on the questions that asked them to imagine structures and processes that must not yet be completely clear to them. Covitt, Gunckel, and Anderson (2009) shared similar observations and concluded that what students understood was limited by what they could directly observe, which left out large scale systems like watersheds and invisible processes like evaporation.

Assessment recommendations. Question 2 asks students, "Which item best illustrates a watershed?" Changing the wording to "Which item best illustrates the shape of a watershed?" may help students better connect with their understanding of the structure and function of a watershed rather than perhaps only its capacity to hold water.

Question 3 asks, "Which option best describes the two elements most responsible for the movement of water within a watershed?" I am curious if the 
choice of the word 'elements' is a term that may incorrectly push students toward considering wind, as in 'out in the elements.' Other than replacing 'elements' with 'things,' which I find awkward, or 'forces' or 'items' which seem misleading, I am unsure of what term could be substituted to represent the sun, the moon, wind, and gravity.

Question 7 reads: "Much of the rainwater that falls on our community makes its way to [Local] Lake, and from there, to" - then lists the options of the most immediate river, the river that river empties into, the Pacific Ocean the larger river empties into, all of the above, and none of the above. Recall that the intention behind this question was to get at both where water goes when it leaves the local community, as well as the nested nature of watersheds. Perhaps this question would be better suited broken into two questions, one that gets at the path of water as it leaves the community, and one that gets at the nested nature of watersheds. The question about the path of water could offer different ordering of correct and incorrect local bodies of water. The question about watersheds could ask, "[Local] Lake is in which of the following watersheds?" and offer some options with only one watershed, some with two watersheds, and the correct option listing the [Nearby] River, the Columbia River, and the Pacific Ocean Watersheds.

Curriculum recommendations. While the data indicates success in increasing students' understand of watersheds and watershed function overall, analysis of the assessment pointed to several remaining challenges to teaching 
this core concept. The most frustrating finding of my analysis was that on the post-assessment, more than $40 \%$ of students identified an illustration of either a water tower or a shed as representing a watershed. After weeks of curriculum with 'Watershed' in the title, these students still had an unclear or completely inaccurate mental picture of a watershed as a human-built structure for storing water. Whether this is the result of unclear lessons or pervasive misconceptions I do not know, but I do know that making sure students can correctly visualize and describe a watershed is the cornerstone of improvements to be made to this curriculum.

Giving students a clear mental image of a complex, often-invisible system like a watershed is no easy task. Unlike individual components of watersheds, such as bodies of water, land formations, and the built world, watersheds are interconnected systems that cannot be easily observed in their entirety. We can watch precipitation land and to some degree see runoff in action, but the bulk of the watershed system is hidden from view by processes happening underground, invisibly in the air around us, and governed by large-scale topography. We can take students out into the environment to observe some of these components, but getting the complete picture is going to take more effective modeling. These could be physical models that accurately represent parts of the watershed, interactive animated models available digitally, or entirely different kinds of models - but they need to be models students can observe and manipulate. During the process of creating this curriculum, several colleagues and I spent 
many hours brainstorming, building, and testing models, as well as looking for them online. Of the models we created or found, none of them seemed representational enough and we worried that they would introduce new sources of confusion. A few simple models have been built into lessons within the existing curriculum but the assessment data suggests the need for further modeling. Perhaps using synonyms for watershed such as basin and catchment would be useful in helping students visualize watersheds accurately.

Without researching it further myself I cannot say for sure, but my observations as an elementary school teacher lead me to believe students are comfortable with the water cycle well before they learn about watersheds. I imagine this is because typical teaching of the water cycle, especially for younger children, generally leaves the land out of the equation, focusing instead on the evaporation, condensation, and precipitation cycle. Infiltration, groundwater recharge, and the water table seem to be left out entirely, as are what happens to runoff and the impacts attributed to it. Are we creating misconceptions in our students by not bringing the land into our discussions of the water cycle from the very beginning? Countless important science concepts exist within the context of the watershed, yet the watershed itself is not often taught.

\section{Objective 2: Describe Impervious Surfaces and Connect Their Impact to the Watershed}

The questions aligned to Objective 2 also showed statistically significant growth between pre- and post-assessment. Objective 2 had a standard deviation 
of 1.3317 and a $p$-value of $<0.0001$. Again, these results provided a strong rejection of the null hypothesis which points to a significant gain in student knowledge and skill. Within the assessment, Objective 2 was represented by four questions: 10-12 and 18. Questions 10 and 11 were more successful with scores of $89 \%$ and $95 \%$ of students answering correctly respectively, whereas questions 12 and 18 came in low with scores of $61 \%$ and $58 \%$ respectively.

Strengths. Questions 10 and 11 show strong gains between the pre- and post-assessment. Question 10 showed a 13\% increase from the pre-assessment data. In this case a strong majority of students (89\%) were able to identify that runoff from paved streets generally flows into ditches or storm drains. Question 11 showed the strongest gains of the entire assessment, up 38\% from pre- to post-assessment. The question asked: "Look to the labeled picture below: which option lists all of the impervious surfaces?" Five lists of three to six familiar outdoor surfaces were provided as options. Option "B, roof, paved walkway, rock" was the correct answer, as all the other options included a pervious surface such as soil, lawn, or gravel. On the pre-assessment, just over half of the students $(57 \%)$ answered correctly, making it the fifth-highest scoring question before the curriculum was taught. On the post-assessment, question 11 had the highest percentage of students answering correctly (95\%). With a 38\% increase in correct answers from pre-assessment to post-assessment, this question demonstrated a clear gain in student understanding. 
Figure 3: Objective 2 Strengths

\begin{tabular}{|c|c|c|c|}
\hline Question from the Pre- and Post-Assessment & Mark & \# & $\%$ \\
\hline \multirow{7}{*}{$\begin{array}{l}\text { 10. When heavy rain falls on a paved street, } \\
\text { a. most of it stays there until it evaporates. } \\
\text { b. most of it is absorbed by the pavement. } \\
\text { c. most of it sinks into the ground through the pavement. } \\
\text { d. most of it gets carried away by vehicles. } \\
\text { e. most of it flows off the road into ditches or storm drains. }\end{array}$} & A & 14 & $5 \%$ \\
\hline & B & 2 & $1 \%$ \\
\hline & C & 6 & $2 \%$ \\
\hline & D & 6 & $2 \%$ \\
\hline & $E$ & 238 & $89 \%$ \\
\hline & None/Two & 0 & $0 \%$ \\
\hline & \multicolumn{2}{|c|}{ Gain from Pre: } & $13 \%$ \\
\hline \multirow{3}{*}{$\begin{array}{l}\text { 11. Look to the labeled picture below: which option lists all of the } \\
\text { impervious surfaces? } \\
\text { a. Paved walkway, soil, lawn, gravel }\end{array}$} & A & 3 & $1 \%$ \\
\hline & $\mathrm{B}$ & 252 & $95 \%$ \\
\hline & C & 3 & $1 \%$ \\
\hline \multirow{4}{*}{$\begin{array}{l}\text { b. Roof, paved walkway, rock } \\
\text { c. Lawn, plants, tree } \\
\text { d. Soil, gravel, rock, roof } \\
\text { e. Plants, soil, tree, rock, gravel, lawn }\end{array}$} & $\mathrm{D}$ & 6 & $2 \%$ \\
\hline & $\mathrm{E}$ & 2 & $1 \%$ \\
\hline & None/Two & 0 & $0 \%$ \\
\hline & \multicolumn{2}{|c|}{ Gain from Pre: } & $38 \%$ \\
\hline
\end{tabular}

Areas for improvement. Questions 12 and 18 showed relatively weaker gains between pre- and post-assessment. The number of students answering question 12 correctly more than doubled from $67(25 \%)$ to $161(61 \%)$ for a gain of $35 \%$, but this was still not enough to meet the threshold for strong post-assessment results. Unfortunately, many students were still unable to identify which of the options listed was not an impact of impervious surfaces. However, the fact that the question was phrased in the negative may have had an impact on how students answered. The correct answer was " $\mathrm{A}$, the lake has less nutrients for algae", as in "the lake having less nutrients for algae is not an impact of impervious surfaces", because phosphates in suburban runoff actually result in more nutrients for algae. Again, it is unclear whether the problem with student 
Figure 4: Objective 2 Areas for Improvement

\begin{tabular}{|c|c|c|c|}
\hline Question from the Pre- and Post-Assessment & Mark & $\#$ & $\%$ \\
\hline \multirow{3}{*}{$\begin{array}{l}\text { 12. Which of the following is not an impact of impervious surface? } \\
\text { a. The lake has less nutrients for algae }\end{array}$} & A & 161 & $61 \%$ \\
\hline & $\mathrm{B}$ & 56 & $21 \%$ \\
\hline & $\mathrm{C}$ & 14 & $5 \%$ \\
\hline \multirow{4}{*}{$\begin{array}{l}\text { b. Creeks that dry up in summer } \\
\text { c. Loss of habitat for plants and animals } \\
\text { d. Erosion in streams } \\
\text { e. Water entering streams is polluted }\end{array}$} & $\mathrm{D}$ & 27 & $10 \%$ \\
\hline & $E$ & 6 & $2 \%$ \\
\hline & None/Two & 2 & $1 \%$ \\
\hline & \multicolumn{2}{|c|}{ Gain from Pre: } & $35 \%$ \\
\hline \multirow{7}{*}{$\begin{array}{l}\text { 18. Look to the half sheet of paper with a gray shape and grid. } \\
\text { Follow the instructions and record your answer by selecting one } \\
\text { of the options below. } \\
\text { a. } 30 \text { square meters } \\
\text { b. } 40 \text { square meters } \\
\text { c. } 50 \text { square meters } \\
\text { d. } 60 \text { square meters } \\
\text { e. It is impossible to estimate without more information }\end{array}$} & A & 16 & $6 \%$ \\
\hline & B & 154 & $58 \%$ \\
\hline & C & 66 & $25 \%$ \\
\hline & $\mathrm{D}$ & 17 & $6 \%$ \\
\hline & $E$ & 4 & $2 \%$ \\
\hline & None/Two & 9 & $3 \%$ \\
\hline & \multicolumn{2}{|c|}{ Gain from Pre: } & $12 \%$ \\
\hline
\end{tabular}

This shows the half-sheet of paper students were given for question 18. The image has been reduced in size for the purposes of this document.

The gray shape below represents the aerial view of a building surrounded by grass. Find the area of the impervious surface in square meters $\left(\mathrm{m}^{2}\right)$.

You can draw and write on this paper.

Use your answer to choose the answer on the test packet that most closely matches your answer.

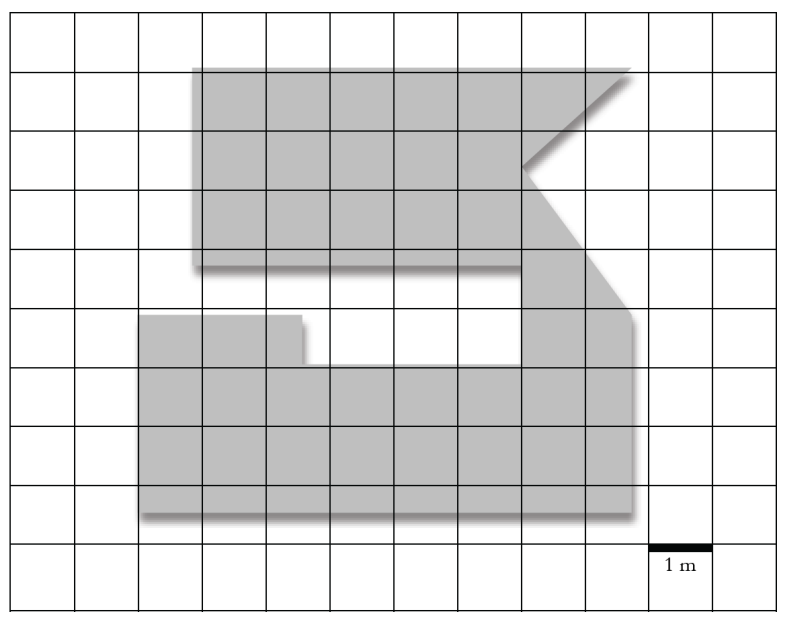

Work space

Total area of shape: square meters, or $\mathrm{m}^{2}$ 
performance on this question is due in part to how the question was asked, so these findings suggest a need for improvement of the assessment tool in addition to a greater emphasis on ecological impacts attributed to impervious surfaces.

Question 18 had the lowest percentage of post-assessment correct answers within Objective 2. This question asked students to demonstrate their understanding of and ability to calculate the area of an impervious surface using a fictional map with a grid overlay (similar to materials used within the curriculum). The percentage of students who got this question correct on the preassessment (46\%) only went up $12 \%$ (to $58 \%$ ) on the post-assessment, which was one of the lowest gains from pre- to post-assessment.

In this instance, I think the problem lies with the way that the answer options were presented. Had they been presented as ranges instead of whole numbers, I believe more students would have answered correctly. Depending upon how they find the area of the impervious surface, students would probably get a number of square meters in the low to mid forties. Those trying to take into account all the tiny slivers of a square would probably get a number closer to 45 square meters. If those students then round up, they are pushed from the correct option of "B, 40 square meters," to the next closest, but incorrect option of " $\mathrm{C}, 50$ square meters." The other issue unique to this question was that 9 students left this question blank, which is represented as 'None' in the Figure 2 data tables. This is more than all of the other 'None' totals combined for the whole assessment. Those 9 individuals represent just over $3 \%$ of the students, but it 
may speak to a greater confusion around where to answer this question, whose answer sheet was not a part of the reusable assessment packet but was printed on a separate half-sheet of paper.

The image to accompany question 18 was not made a part of the reusable packet because I knew that some students would, by accident or out of necessity, make checkmarks, tallies, or other marks in their efforts to find the solution and I did not want markings left in the packet that other students would see. Another possible source of confusion is that the image of the impervious surface' itself has a shadow on it, just like the areal photos the students worked from during the unit. In hindsight, it is possible that teachers may have had to make additional copies of the half-sheet for their students to use and the image quality may have blurred the difference between the impervious surface and its shadow and made the shape appear larger than it really was, pushing them again toward the incorrect estimation of 50 square meters.

The goal of Objective 2 was for students to describe impervious surfaces and connect their impact to the watershed. Strong scores on questions 10 and 11 show that students are confident about what impervious surfaces are and that runoff from roadways collects in ditches and storm drains. What is less clear is whether or not students understand the impacts of those impervious surfaces on the watershed as there is only one question directly assessing that concept (question 12) and the question itself may have gotten in the way of interpreting student knowledge. 
Many of the strategies Endreny (2009) used to successfully teach urban fifth-graders about infiltration and impervious surfaces were very similar to strategies used in the WEDU curriculum. Endreny also did some things differently that may have led her students to have a richer understanding of the impacts of impervious surfaces on the watershed. First, her students observed infiltration, impervious surfaces, and a nearby brook throughout the seasons, whereas our curriculum was all conducted in the spring. Second,

[t]o gain a greater awareness of the pollutants in the brook, the students conducted water quality tests for $\mathrm{pH}$, Dissolved Oxygen, Phosphate, Nitrate, fecal coliform and turbidity at the brook. The students then read about the sources of these pollutants on several government and educational internet sites and then wrote a paper describing the water quality of the local brook. (p. 512)

These aspects of Endreny's research likely allowed the students in her study to develop a clearer understanding of the impacts of impervious surfaces on the watershed and a more direct understanding of the links between human activity and those impacts. As of the first generation of the WEDU post-assessment, there were no questions directed completely at assessing student understanding of human impacts on the watershed, so we do not have data to analyze on this topic.

Assessment recommendations. Question 12 asks, "Which of the following is not an impact of impervious surfaces?" The biggest problem with this question may be that it is asking for a non-example which could be confusing for students, especially as the correct option, "The lake has less nutrients for algae," 
contains the word 'less.' In reality, one impact of impervious surfaces is eutrophication of lakes due to an increase in nutrients for algae. The best solution I see for this problem would be to break it into more than one question highlighting the impacts of impervious surfaces. That way, teachers will also have more insight into students' understanding of those impacts such as how erosion is caused or habitat is lost, for example. Doing so would also give Objective 2 greater representation within the assessment instrument.

Question 18 asked students to "Look to the half sheet of paper with a gray shape and grid. Follow instructions and record your answer by selection one of the options below." The half sheet itself read, "The gray shape below represents the aerial view of a building surrounded by grass. Find the area of the impervious surface in square meters $\left(\mathrm{m}^{2}\right)$." In hindsight, there are a couple of problems with this question. First, the complete directions should be on both the test packet and the half-sheet to reduce confusion. Second, the shadow on the shape should be removed to reduce confusion about the size of the area, or a real photo, similar to those used in the lessons, should be used in its place. Third, instead of listing options such as $30,40,50$, and 60 square meters, ranges should be given as options to avoid rounding errors: 30 - 39 square meters, 40 49 square meters, etc. Lastly, perhaps this question would be better suited for formative use during lessons 12 though 15 when it would be most useful to know if students are correctly using this skill. 
Curriculum recommendations. Most educational illustrations of watersheds show areas of high relief, such as mountain ranges, followed by areas of pristine wilderness including creeks, rivers, and lakes, which empty into the sea. I recognize the need to simplify for an illustration but what such images leave out is us - the human-built world and all that comes with it. We want our students to learn not just about watersheds and watershed function in the abstract, but also about their own watershed and the impacts human developments have had, especially because we are asking them to think about remediating impervious surfaces. Following Endreny's (2009) use of field excursions, if time and resources allow, adding a day or two to walk to a nearby creek could be fruitful. Testing water quality for evidence of direct and indirect human impact - particularly $\mathrm{pH}$, phosphates, and turbidity - could help students understand non-point source pollution happening in their own back yard, their local watershed. Students could also compare water quality data after a period of time with no rain to data taken a day after a significant storm event. Scheduling such activities would be difficult given the unpredictability of the weather, but these have the potential of being immediate and powerful instructional tools. Hopefully students more connected to their watersheds will grow into adults more invested in taking care of their watershed both in how they handle their own runoff and how they respond to water quality initiatives.

\section{Objective 3: Perform the Engineering Design Process}


Objective 3 , represented by $13,14,15$, and 17 , assessed student understanding and skill with respect to the engineering design process. Questions 13 and 14 were counted as high scoring, with correct answer percentages of $84 \%$ and $76 \%$ respectively, whereas students struggled more with questions 15 and 17 , which had scores of $62 \%$ and $65 \%$ respectively.

Recall that the curriculum was organized such that the engineering design lessons and experiences were concentrated at the end of the unit. This was so that students could use engineering design practices to develop a solution to mitigate the effects the impervious surfaces within their schoolyard had on their watershed. Unfortunately, as mentioned, the school year ran out before they had a chance to finish the curriculum, and students had to take the post-assessment after only lesson 15 or 16 of 24 . The concept of engineering design was not introduced until lesson 7 and the topic of Pugh charts - the engineering design tool that was a primary tool during the engineering design portion of the curriculum and the basis of three-fourths of the Objective 3 questions - was not introduced until lesson 13. For this reason I presumed students would make minimal gains in regards to this objective. This made the statistical significance of student gains expressed in Table 3 (standard deviation of 1.2213 and a $p$-value of $<0.0001$ ) somewhat surprising. Even without finishing the engineering design portion of the WEDU curriculum, students made significant learning gains.

Strengths. With correct answer percentages of $84 \%$ and $76 \%$ respectively, questions 13 and 14 were included in the high scoring category. In 
Figure 5: Objective 3 Strengths

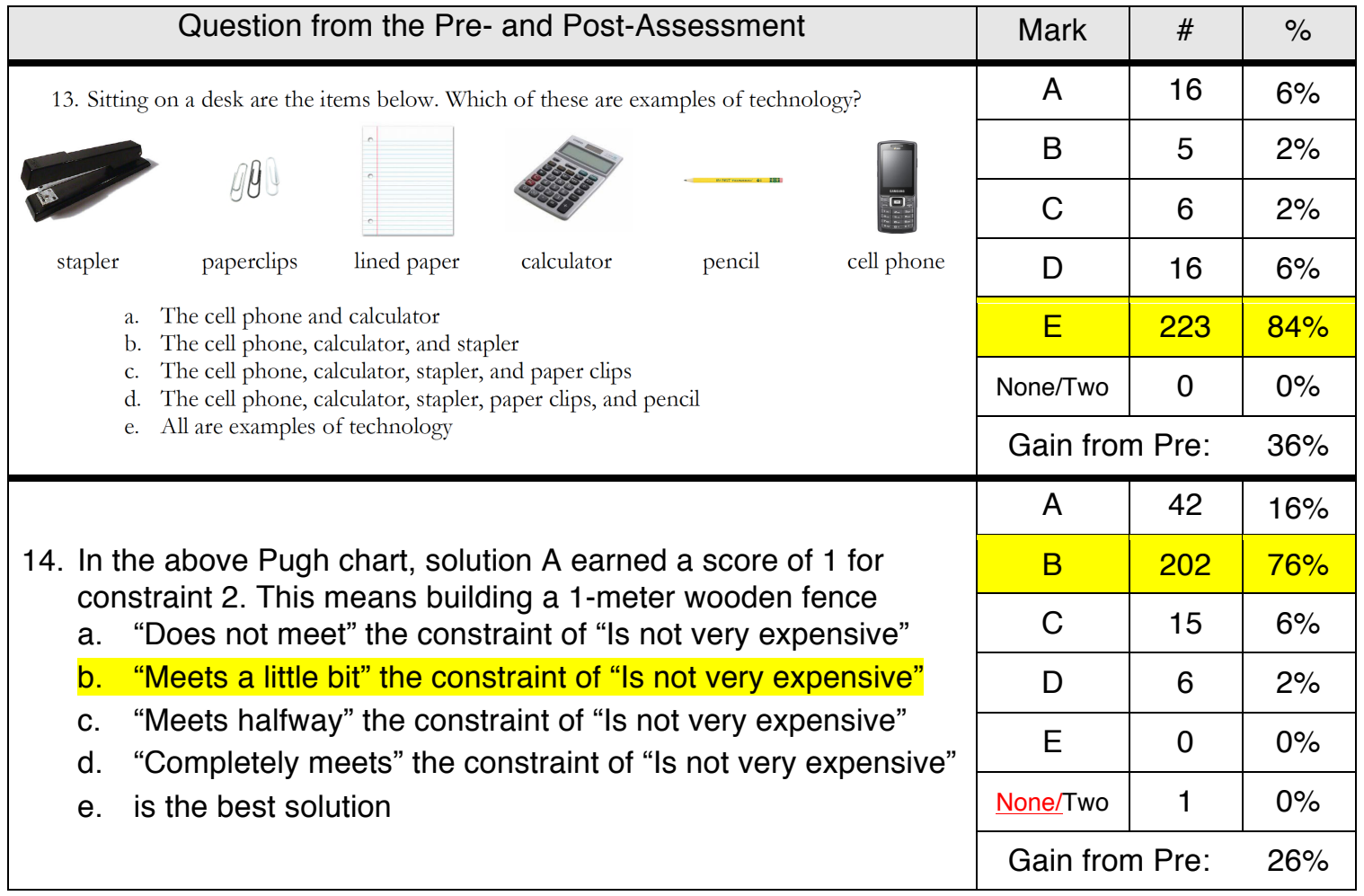

lesson 7 students were introduced to the definition of technology as any change to the natural world made to satisfy human needs or wants. Technology as we defined it is the end product of engineering. This is a notable difference from the current tendency, particularly among youth, to consider technology to be limited to items with batteries and screens. Question 13 asked students to view a list of items and determine which of them are examples of technology. As shown in Figure 5, the six possible answers included a stapler, paperclips, a sheet of lined notebook paper, a calculator, a pencil, and a cell phone. On the pre-assessment only $48 \%$ of the students gave the correct answer. On the post-assessment, there was a sharp increase with $84 \%$ choosing the correct answer, resulting in a $36 \%$ gain in student scores. 
The progression of engineering design $\mathrm{K}-12$ education in Appendix I of the Next Generation Science Standards (NRC, 2013) is explained as follows:

At the middle school level, students learn to sharpen the focus of problems by precisely specifying criteria and constraints of successful solutions, taking into account not only what needs the problem is intended to meet, but also the larger context within which the problem is defined, including limits to possible solutions. Students can identify elements of different solutions and combine them to create new solutions. Students at this level are expected to use systematic methods to compare different solutions to see which best meet criteria and constraints, and to test and revise solutions a number of times in order to arrive at an optimal design. (p. 4)

As written, the Watershed and Engineering Design Unit (WEDU) curriculum addresses this progression. The larger context, the local watershed and the impacts to that watershed by impervious surfaces, are investigated and defined in the first half of the curriculum. Students explore criteria and constraints, existing mitigations and their own ideas for mitigation, as well as entertain the creation of designs that take characteristics from different sources. Using Pugh charts, students systematically weigh mutually agreed upon criteria and constraints as they evaluate their design solutions. Through collaborative iterations students improve their designs and share them with peers and their teacher. All of these steps are a part of the WEDU.

Below is the Pugh chart used in questions $14-17$. A Pugh chart is a matrix tool commonly used in fields such as architecture, urban planning, or landscape architecture, to aid in making decisions when there are multiple factors to consider. For the purposes of this curriculum, students scored several solution 
Figure 6: The Pugh Chart

The Pugh chart below is take from the pre- and post-assessment and was used with questions 14,15 , and 17. Recall that question 16 was not used because it contained a typo. The chart has been reduced in size for the purposes of this document.

For questions $14-17$ refer to Gloria's Pugh chart below.

\begin{tabular}{|c|c|c|c|c|c|}
\hline \multirow{2}{*}{$\begin{array}{l}\text { PROBLEM TO } \\
\text { BE SOLVED: } \\
\text { Evaluate each } \\
\text { solution against each } \\
\text { criterion and } \\
\text { constraint } \\
\text { 0: Does not meet } \\
\text { 1: Meets a little bit } \\
\text { 2: Meets halfway } \\
\text { 3: Completely meets }\end{array}$} & \multicolumn{5}{|c|}{ Rabbits keep eating the vegetables that I am growing for my family } \\
\hline & 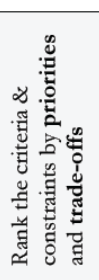 & $\begin{array}{l}\text { SOLUTION A } \\
\text { Build a } 1 \text { meter } \\
\text { wooden fence } \\
\text { mammmmm }\end{array}$ & $\begin{array}{l}\text { SOLUTION B } \\
\text { Only grow plants } \\
\text { that rabbits } \\
\text { don't like to eat }\end{array}$ & $\begin{array}{l}\text { SOLUTION C } \\
1 \text { meter chicken- } \\
\text { wire and stake } \\
\\
\end{array}$ & $\begin{array}{l}\text { SOLUTION D } \\
\text { Set rabbit traps } \\
\text { and let them out } \\
\text { somewhere else }\end{array}$ \\
\hline $\begin{array}{l}\text { CRITERION } 1 \\
\text { Have homegrown } \\
\text { vegetables to eat }\end{array}$ & 1 & 3 & 1 & 3 & 2 \\
\hline $\begin{array}{l}\text { CRITERION } 2 \\
\text { Easy to maintain }\end{array}$ & 4 & 3 & 3 & 2 & 1 \\
\hline $\begin{array}{l}\text { CRITERION } 3 \\
\text { Nice enough to } \\
\text { look at }\end{array}$ & 5 & 3 & 3 & 2 & 2 \\
\hline $\begin{array}{l}\text { CONSTRAINT } 1 \\
\text { Won't hurt the } \\
\text { rabbits }\end{array}$ & 3 & 3 & 3 & 3 & 2 \\
\hline $\begin{array}{l}\text { CONSTRAINT } 2 \\
\text { Is not very } \\
\text { expensive }\end{array}$ & 2 & 1 & 2 & 3 & 2 \\
\hline $\begin{array}{l}\text { After scoring each solut } \\
\text { against each criterion an } \\
\text { constraint, total the sco } \\
\text { bottom } \Rightarrow\end{array}$ & es at the & 13 & 12 & 13 & 9 \\
\hline
\end{tabular}

ideas against project criteria (the things the solution should do) and constraints (limits on possible solutions) using a Pugh chart similar to the one in Figure 6.

Using the above Pugh chart for question 14, students were asked to explain the meaning of solution A's score of 1 for constraint 2. Seventy-six percent of students correctly attributed it to option "B, 'Meets a little bit' the constraint of 'Is not very expensive"'. Looking at the Pugh chart it might seem like students were given an unfair advantage in answering the question because the upper-left-hand 
corner of the chart itself explains the scoring throughout the chart; however, that resource was also available during the identical pre-assessment and only $50 \%$ of students answered it correctly the first time around. There was a $26 \%$ gain in students answering the question correctly despite the incomplete teaching of the curriculum.

\section{Areas for improvement.}

Figure 7: Objective 3 Areas for Improvement

\begin{tabular}{|c|c|c|c|}
\hline Question from the Pre- and Post-Assessment & Mark & $\#$ & $\%$ \\
\hline \multirow{7}{*}{$\begin{array}{l}\text { 15. According to the Pugh chart, Gloria should choose the chicken } \\
\text { wire fence. Why? } \\
\text { a. It had the highest total score } \\
\text { b. It had the lowest total score } \\
\text { c. It scored higher than solution A in constraint 2, which had } \\
\text { high priority } \\
\text { d. It scored higher than solution D in criterion 2, which had low } \\
\text { priority } \\
\text { e. It came in second place in criterion } 3\end{array}$} & A & 66 & $25 \%$ \\
\hline & B & 5 & $2 \%$ \\
\hline & $\mathrm{C}$ & 164 & $62 \%$ \\
\hline & $\mathrm{D}$ & 21 & $8 \%$ \\
\hline & $E$ & 9 & $3 \%$ \\
\hline & None/Two & 1 & $0 \%$ \\
\hline & \multicolumn{2}{|c|}{ Gain from Pre: } & $18 \%$ \\
\hline \multirow{7}{*}{$\begin{array}{l}\text { 17. According to the chart, Gloria believes that } \\
\text { a. Solution } C \text { would be harder to maintain that Solution } A \\
\text { b. Solution B is more expensive than Solution } A \\
\text { c. Solution } D \text { is less attractive than solution } C \\
\text { d. Solution B is more dangerous for the rabbits than Solution } \\
\text { D } \\
\text { e. All of the solutions would allow Gloria to grow enough } \\
\text { vegetables for her family }\end{array}$} & A & 173 & $65 \%$ \\
\hline & $\mathrm{B}$ & 16 & $6 \%$ \\
\hline & C & 26 & $10 \%$ \\
\hline & D & 19 & $7 \%$ \\
\hline & $\mathrm{E}$ & 30 & $11 \%$ \\
\hline & None/Two & 2 & $1 \%$ \\
\hline & \multicolumn{2}{|c|}{ Gain from Pre: } & $25 \%$ \\
\hline
\end{tabular}

Question 15 had the lowest percentage of correct answers on the postassessment in Objective 3. This question asks, "According to the Pugh chart [Figure 6], Gloria should choose the chicken wire fence. Why?" This fact first question (Keeley, 2008) gives students the answer to the big question of which solution should Gloria pick, but asks them to explain it. The first option snagged nearly a quarter of all student answers (25\%) with "A, 'It had the highest total 
score."' A quick glance at the chart shows that option A is partially true, as the chicken wire fence earned a score of 13 points - but so did the wooden fence. For that reason, option " $\mathrm{C}$, It scored higher than solution $\mathrm{A}$ [the wooden fence] in constraint 2, which had high priority," was the correct answer. Only $62 \%$ of students answered this question correctly.

This is a complex question that required students to slow down and read and interpret the Pugh chart, then examine options one at a time to determine which options were accurate and take into consideration the priorities or relative importance of the criteria and constraints. Despite question 15 likely being the most difficult question on the assessment, I think it is a fair question and one that students should be able to answer correctly by the completion of the entire curriculum. There was an $18 \%$ increase in correct responses to $62 \%$ on the postassessment, up from $43 \%$ on the pre-assessment.

Students are again challenged to slow down and carefully consider each option for question 17, which asks them to use the Pugh chart to interpret the fictional Gloria's thoughts. Only $65 \%$ of student answered this question correctly. A nearly $25 \%$ increase from the $40 \%$ who answered question 17 correctly on the pre-assessment shows strong gains in student understanding, but not strong enough to put this question in the strong scoring category.

Although the Objective 3 questions did not show the strongest postassessment scores out of the three objectives, they did show the largest margin of gain from pre- to post-assessment ( $26 \%$ on average), which resulted in a 
statistically significant gain as illustrated in Table 3. The key takeaway from this is that students did make gains regarding engineering design knowledge and skills, even though they did not have a chance to engage with many of the engineering design lessons that were omitted due to time constraints. To draw a parallel from the literature, Foster and Ganesh (2013) found that the inclusion of engineering design in their unit on the human heart doubled the length of time required to teach their science content. Granted the engineering design process was itself a main objective in the WEDU, but its inclusion certainly accounted for more than half of the curriculum. Despite the increased time needed, the students in Foster and Ganesh's research made statistically significant gains in their content learning. Their positive results leave me hopeful that, given more time to complete the unit in future years, students can make even stronger gains in content knowledge engineering design skill and understanding.

To review, despite the strengths and weaknesses within the individual questions, the students, on the whole, made statistically significant learning gains in relation to all three objectives. Recall that in the literature, the benefits of watershed education and engineering design education have both been documented many times over independent of one another. The results of this curriculum evaluation strongly suggest that the Watershed and Engineering Design Unit curriculum is a valid way to teach watershed education using engineering design practices. Although this study was limited, I hope this unit can be a starting point for educators in a variety of other settings and situations. 
Assessment recommendations. Question 15 reads, "According to the Pugh chart, Gloria should choose to the chicken wire fence. Why?" Unfortunately, clarification of the options involves a long list of wordy options, which can be confusing for students. Options C and D could be prefaced with "It had the highest score and..." With the addition, the correct option would balloon to: "It had the highest score and it scored higher than solution A in constraint 2, which had high priority." Without that addition, students may have felt like they needed to go with option A, which read, "It had the highest total score." Another solution may be to convert this question from multiple-choice to short answer, requiring students to explain their rationale.

Curriculum recommendations. The data I analyzed came from students who did not have a chance to experience the bulk of the engineering design portion of the Watershed Engineering Design Unit because of previously discussed time limitations. For that reason, it seems premature to use this round of assessment outcomes to make judgments about the effectiveness of the engineering design portion of the curriculum. I would recommend instead that a similar analysis be conducted with subsequent WEDU data following a year where adequate time was allotted and students were able to complete the unit in its entirety.

\section{Recommendations for Future Practice}

Just as students had varied background knowledge going into the preassessment, so did the teachers going into teaching this unit for the first time. 
Recall that the setting for this evaluation was a district that had just restructured their K-8 schools such that sixth-grade students moved from self-contained classrooms in elementary schools to a middle school model. This created the need for four new sixth-grade science teachers. Two came from within the science departments from the middle schools, were they had been teaching seventh- and eighth-grade students, and two came from teaching self-contained elementary sixth-grade. Only one teacher had previously taught an engineering design unit.

I believe it would have been beneficial, given the resources and the time, to have provided the teachers some professional development in the form of a multi-session training that would equip them with background knowledge, walk them through the curriculum, answer any questions, and troubleshoot any concerns about implementation. Even more ambitious, in the future, would be to engage the teachers in a more extensive professional development in cooperation with the associated university or a local STEM education organization. With additional time and resources, teachers could learn more about the Framework for K-12 Science Education (NRC, 2012), the Oregon Environmental Literacy Plan (Oregon Environmental Literacy Task Force, 2010), and application of the STEM conceptual knowledge construct as described by the STEM Common Measurement System (Saxton et al., 2014) for purposes of bettering the WEDU curriculum and assessment tool. As is, we did meet briefly twice and were in contact throughout the unit via email. Although it was 
purposefully not a part of my formal analysis, seeing student post-assessment and learning gains as segregated by teacher caused me to wonder what impact a teacher's comfort and familiarity with the material had on his or her students' scores. The addition of professional development for the teachers could help the unit be as successful as possible and could also be an interesting topic of further study. 


\section{Conclusion}

The existing educational literature contains studies focusing on watershed education and studies focusing on engineering design education, but there is little literature documenting the intersection of the two. This research seeks to fill that gap by providing an evaluation of a new curriculum that incorporates watershed education with engineering design education. My primary purpose in creating the Watershed and Engineering Design Unit was to fulfill a need for curriculum that would teach suburban middle-school students about watersheds, the effects of impervious surfaces on those watersheds, and have them design and improve mitigation models through the engineering design process. The creation and evaluation of this curriculum was praxis-driven rather than research-driven and the results of this evaluation will be used to help modify both the curriculum and the assessment tool for future iterations of the unit, as it will continue to be used annually.

Through a 24-lesson unit, 20 classrooms of suburban sixth-graders at two middle schools experienced a place-based watershed and engineering design unit of study in 2013. Working in small groups, students learned about the structure, function, and health of their local watersheds. Students learned about the negative effects of impervious surfaces and then, using the engineering design process, created and rated solutions to mitigate these effects on their own school campuses. The goal of this research was to determine the effectiveness of the curriculum in terms of student gains in understanding of three learning 
objectives: (1) watershed function, (2) the impact of impervious surfaces, and (3) the engineering design process.

A 17-question, multiple-choice pre- and post-assessment asked the students to share what they knew to begin with, and after the unit, what they had learned. Looking at average pre-assessment and average post-assessment scores, separated by objective, students showed clear learning gains in all three objectives. Objective 1 scores rose from an average of $43 \%$ on the preassessment to an average of $62 \%$ on the post-assessment, for a gain of $19 \%$. Objective 2 scores saw an increase of $25 \%$ from $51 \%$ on the pre- to $76 \%$ on the post-assessment. Objective 3 scores also increased, from $45 \%$ on the pre- to $72 \%$ on the post-assessment, gaining $26 \%$. The same pre- and post-assessment data was used to run unsummarized, lower-tailed, paired sample $t$-tests by objective. The results, for each of the three objectives (where the level of significance had been set at 0.05 ), was a $p$-value of $<0.0001$. This shows a strong rejection of the null hypothesis and clear evidence that students made significant learning gains. The process of analyzing the data, including the distribution of answers chosen for each question, has illuminated several areas worthy of further study.

The WEDU was first used in the spring of the $2012-2013$ school year and the data examined in this research emanates from the work of 266 students that year. This spring, the curriculum will be used for a fourth year. One of the teachers to pilot the unit will still be teaching it, along with his other sixth-grade 
science teacher colleagues new to the role since the introduction of the WEDU. I look forward to sharing my formal evaluation and hearing about how teaching the unit has been going and in what ways it has changed.

I expect that the WEDU, as a living curriculum, will grow and change with time. It is my hope that the recommendations I made to the curriculum and assessment, as a result of my analyses, will be incorporated into future iterations of the curriculum, and the teachers using it will have ample time to familiarize themselves with the WEDU and background information. Soon the curriculum will be available online so that other schools may access the lessons, assessment instrument, and other materials in order to adapt it for use at their own schools.

Lastly, I would be interested to see a follow-up evaluation of the Watershed Engineering Design Unit after it is updated and taught to its completion this coming year or in years to come. Broadening the scope of the evaluation to include student work samples, student and teacher interviews, and, if possible, data from more than one school district would result in a unique and more substantial contribution to the literature. 


\section{References}

American Association for the Advancement of Science. (1990). Science for All Americans. New York, NY: Oxford University Press.

American Association for the Advancement of Science. (1993). Benchmarks for Science Literacy. New York, NY: Oxford University Press

Covitt, B. A, Gunckel, K. L., \& Anderson, C. W. (2009). Students' Developing Understanding of Water in Environmental Systems. Journal of Environmental Education, 40(3), 37-51.

Donahue, T. P., Lewis, L. B., Price, L. F., \& Schmidt, D. C. (1998). Bringing science to life through community-based watershed education. Journal of Science Education and Technology, 7(1), 15-23. Retrieved from http://www.jstor.org/stable/40188641

Endreny, A. H. (2009). Urban 5th graders conceptions during a place-based inquiry unit on watersheds. Journal of Research in Science Teaching, 47(5), 501-517. http://doi.org/10.1002/tea.20348

Foster, C., \& Ganesh, T. (2013). Engineering the Human Heart in the Sixth Grade Classroom.

Katehi, L., Pearson, G., \& Feder, M (Eds.). (2009). Engineering in K-12 Education: Understanding the status and improving the prospects. Washington, DC: National Academy of Engineering and National Research Council of the National Academies. 
Klahr, D., Triona, L. M., \& Williams, C. (2007). Hands on What? The Relative Effectiveness of Physical Versus Virtual Materials in an Engineering Design Project by Middle School Children, 44(1), 183-203. http://doi.org/10.1002/tea Meinershagen, R. (2014). Solving Local Watershed Problems: A measurement of student success with the engineering design (Proposed thesis). Portland, OR: Portland State University.

National Research Council. (1999). 1996 National Science Education Standards. Washington DC: National Academy Press.

National Research Council. (2012). A Framework for K-12 Science Education: Practices, Crosscutting Concepts, and Core Ideas. Washington, DC: The National Academies Press.

No Oregon Child Left Inside. (2010). Oregon Environmental Literacy Plan: Toward a Sustainable Future. Retrieved from ode.state.or.us.

Oregon Department of Education (2012, October 9). [Basin $\left.{ }^{3}\right]$ Junior High School 2011-2012 School Report Card. Retrieved July 26, 2013, from http://www.ode.state.or.us/data/reportcard/RCpdfs/13/13-ReportCard\#\#.pdf

Oregon Department of Education (2012, October 9). [Catchment ${ }^{4}$ ] Junior High School 2011-2012 School Report Card. Retrieved July 26, 2013, from http://www.ode.state.or.us/data/reportcard/RCpdfs/13/13-ReportCard\#\#.pdf

\footnotetext{
${ }^{3}$ School name has been replaced with a pseudonym

${ }^{4}$ School name has been replaced with a pseudonym
} 
Saxton, E., Burns, R., Holveck, S., Kelley, S., Prince, D., Rigelman, N., \& Skinner, E.A. (2014). A common measurement system for K-12 STEM education: Adoption an educational evaluation methodology that elevates theoretical foundations and system thinking. Studies in Educational Evaluation, 40. Retrieved from www.elsevier.com/stueduc.

Schall, L.L.M. (2015). Focus on a STEM, Based in Place, Watershed Curriculum: A confluence of stormwater, humans, knowledge, attitudes, and skills (Masters dissertation). Retrieved from PDX Scholar. Paper 2352.

Shepardson, D. P., Wee, B., Priddy, M., \& Schellenberger, L. (2007). What Is a Watershed? Implications of Student Conceptions for Environmental Science Education and the National Science Education Standards. Science Education, 91(4), 554-578. http://doi.org/10.1002/sce 
April, 2013

\section{Appendix A}

Dear Parent or Guardian:

\section{Reason for this Communication}

You are receiving this parental consent form to both inform you and request your permission for your child to participate in the Watershed Engineering Design curriculum development study.

\section{The Curriculum}

Following recent units on weather and landforms, students will focus in on learning about their local watersheds in this instructional unit. Students will engage in an engineering design project in response to their investigation of the impacts of impervious surfaces (streets, roofs, etc.) on their school campus.

This unit was developed specifically for sixth grade science classrooms in partnership with [Basin Middle School] and [Catchment Middle School] teachers, the [Local] Watershed Council, and the Portland State University Center for Science Education. It has been created to meet [State] content and engineering design standards, as well as the newly published national Next Generation Science Standards.

\section{How it Affects Students}

The regular classroom teachers will teach this unit to all students. Researchers from Portland State University's Center for Science Education will be conducting a study of the Watershed Engineering Design Unit curriculum in order to assess how effectively the student work represents the learning goals of the curriculum in order to identify areas for improvement in the curriculum.

Researchers will only analyze the work of students whose parents/guardians have given consent by signing this form. All copies of student work given to researchers will be made with student names concealed, rendering them anonymous and identifiable only by class.

A small sub-set of students may be asked to participate in a brief interview with a researcher. Participation is voluntary and dependant upon specific parental consent below. Questions would involve content covered by the curriculum as well as students perceptions of the unit lessons and activities. Student responses would have no bearing on their grades, and would be used to make improvements to the curriculum based upon student comments.

Regardless of whether or not students participate in the study, all students will have access to the same instruction and activities. The decision of whether or not to participate in the study will also bave no effect on your student's grade and will not be detrimental to the success of the study. 


\section{Request for Consent}

Your student's teacher, as well as $\quad$ School District's Director of Secondary Education, Dr. _ and Portland State University's Human Subjects Research Review Committee have approved the abovementioned study. Please direct any questions to Stephanie Wagner, Program Coordinator, PSU Center for Science Education:

@pdx.edu / 503.

If you, as the parent or guardian, wish to rescind this agreement, you may do so at any time in writing by sending a letter to the principal of your child's school and such rescission will take effect upon receipt by the school.

\section{Returning this signed form signifies permission for your student to participate in this study.}

Check the box at left to give additional permission for your student to be interviewed by a researcher.

Student name:

Printed name of

Parent/Guardian: Relation to Student:

Signature of Parent/Guardian: Date:

Thank you. 


\section{Appendix B}

\section{Watershed Engineering Design Unit Alignments \\ Aligned to A Framework for K-12 Science Education \& The Next Generation Science Standards}

This unit has been prepared for [City] sixth grade science classrooms in partnership with two generous and helpful local organizations and the Portland State University Master of Science Teaching program, coordinated by Stephanie Wagner.

\begin{tabular}{|c|c|}
\hline 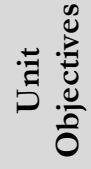 & $\begin{array}{l}\text { 1. Students will explain what a watershed is and how it functions } \\
\text { 2. Students will describe impervious surfaces and connect their impact to the watershed } \\
\text { 3. Students will perform the engineering design process }\end{array}$ \\
\hline 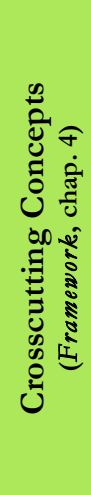 & $\begin{array}{l}\text { Energy and Matter } \\
\text { »Within a natural or designed system, the transfer of energy drives the motion and/or cycling of } \\
\text { matter. (MS-ESS2-4) } \\
\text { Cause and Effect } \\
\text { » Relationships can be classified as causal or correlational, and correlation does not necessarily imply } \\
\text { causation. (MS-ESS3-3) } \\
\text { Influence of Science, Engineering, and Technology on Society and the Natural World } \\
\text { "The uses of technologies and limitations on their use are driven by people's needs, desires, and } \\
\text { values; by the findings of scientific research; and by differences in such factors as climate, natural } \\
\text { resources, and economic conditions. Thus technology use varies from region to region and over } \\
\text { time. (MS-ETSI-2) }\end{array}$ \\
\hline 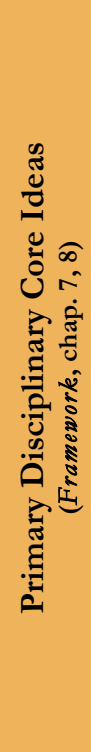 & $\begin{array}{l}\text { MS-ESS2 Earth's Systems } \\
\text { ESS2.C: The Roles of Water in Earth's Surface Processes } \\
\text { »Water continually cycles among land, ocean, and atmosphere via transpiration, evaporation, } \\
\text { condensation and crystallization, and precipitation, as well as downhill flows on land. (MS-ESS2-4) } \\
\text { »Global movements of water and its changes in form are propelled by sunlight and gravity. (MS- } \\
\text { ESS2-4) } \\
\text { MS-ESS3 Earth and Human Activity } \\
\text { ESS3.C: Human Impacts on Earth Systems } \\
\text { » Human activities have significantly altered the biosphere, sometimes damaging or destroying natural } \\
\text { habitats and causing the extinction of other species. But changes to Earth's environments can have } \\
\text { different impacts (negative and positive) for different living things. (MS-ESS3-3) } \\
\text { "Typically as human populations and per-capita consumption of natural resources increase, so do the } \\
\text { negative impacts on Earth unless the activities and technologies involved are engineered otherwise. } \\
\text { (MS-ESS3-3) } \\
\text { MS-ETS1 Engineering Design } \\
\text { ETS1.B: Developing Possible Solutions } \\
\text { "There are systematic processes for evaluating solutions with respect to how well they meet the } \\
\text { criteria and constraints of a problem. (MS-ETS1-2) }\end{array}$ \\
\hline
\end{tabular}




\begin{tabular}{|c|c|c|c|c|}
\hline 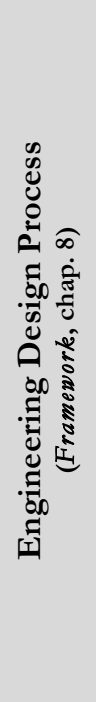 & $\begin{array}{l}\text { Defining \& } \\
\text { Delimiting an } \\
\text { Engineering } \\
\text { Problem } \\
\text { What is a design for? } \\
\text { What are the criteria and } \\
\text { constraints of a successful } \\
\text { solution? } \\
\text { - Criteria and } \\
\text { constraints } \\
\text { - Consideration of } \\
\text { scientific principles } \\
\text { and other relevant } \\
\text { knowledge }\end{array}$ & $\begin{array}{l}\text { Developing Possible } \\
\text { Solutions } \\
\text { What is the process for } \\
\text { developing potential design } \\
\text { solutions? } \\
\text { - Open-ended } \\
\text { brainstorming } \\
\text { - Specify solutions } \\
\text { that meet } \\
\text { requirements } \\
\text { - Create models to } \\
\text { guide development } \\
\text { - Use models to } \\
\text { better understand or } \\
\text { predict design's } \\
\text { performance } \\
\text { - Share designs }\end{array}$ & \multicolumn{2}{|c|}{$\begin{array}{l}\text { Optimizing the Design Solution } \\
\text { How can the various proposed design solutions be } \\
\text { compared and improved? } \\
\text { - Systematic processes for evaluating solutions } \\
\text { with respect to how well they meet the criteria } \\
\text { and constraints } \\
\text { - Comparing different designs could involve } \\
\text { running them through the same kinds of tests } \\
\text { and recording results } \\
\text { - Possibly incorporating successful } \\
\text { characteristics of multiple designs into a new } \\
\text { design } \\
\text { - Iterative process leads to optimal solution } \\
\text { - Describe solution, explain development, } \\
\text { describe features that make it successful }\end{array}$} \\
\hline 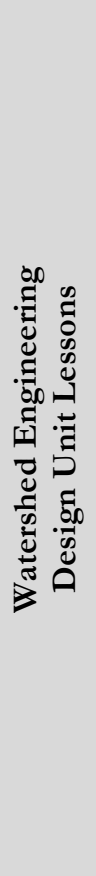 & $\begin{array}{l}\text { 2. Watersheds and the } \\
\text { Water Cycle } \\
\text { 3. Infiltration } \\
\text { Investigation } \\
\text { 4. Runoff and } \\
\text { Impervious } \\
\text { Surfaces } \\
\text { 5. Campus } \\
\text { Calculations } \\
\text { 6. Establish and } \\
\text { Define the Problem } \\
\text { 7. Introduce the } \\
\text { Engineering Design } \\
\text { Process } \\
\text { 8. Choose Criteria and } \\
\text { Constraints } \\
\text { 9. Work sample: } \\
\text { complete } \\
\text { Identifying and } \\
\text { Defining a Problem } \\
\text { to be Solved } \\
\text { (part 1) }\end{array}$ & $\begin{array}{l}\text { 10. Engineering design } \\
\text { teams } \\
\text { 11. Tools for } \\
\text { collecting data on } \\
\text { site } \\
\text { 12. Select sites } \\
\text { 13. Introduce the Pugh } \\
\text { Chart } \\
\text { 14. Introduce } \\
\text { Stormwater } \\
\text { Manual } \\
\text { descriptions of } \\
\text { common solutions } \\
\text { 15. Create a detailed } \\
\text { design } \\
\text { 16. Work sample: } \\
\text { complete } \\
\text { Generating } \\
\text { Possible Solutions } \\
\text { (part 2) }\end{array}$ & $\begin{array}{l}\text { 17. Create data from } \\
\text { the design } \\
\text { 18. Evaluate the } \\
\text { detailed design } \\
\text { 19. Work sample: } \\
\text { complete Testing } \\
\text { Solution(s) and } \\
\text { Collecting Data } \\
\text { (part 3) }\end{array}$ & $\begin{array}{l}\text { 20. Hold a design } \\
\text { charrette } \\
\text { 21. Make } \\
\text { improvements to } \\
\text { the design } \\
\text { 22. Work sample: } \\
\text { complete } \\
\text { Analyzing and } \\
\text { Interpreting } \\
\text { Results (part 4) } \\
\text { 23. Revise and edit } \\
\text { work samples }\end{array}$ \\
\hline 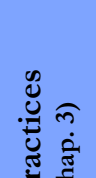 & $\begin{array}{l}\text { Defining Problems } \\
\text { (1) }\end{array}$ & $\begin{array}{l}\text { Constructing } \\
\text { Explanations and } \\
\text { Designing Solutions } \\
\text { (6) }\end{array}$ & $\begin{array}{l}\text { Planning and } \\
\text { Carrying Out } \\
\text { Investigations (3) }\end{array}$ & $\begin{array}{l}\text { Obtaining, } \\
\text { Evaluating, and } \\
\text { Communicating } \\
\text { Information (8) }\end{array}$ \\
\hline $\begin{array}{l}\dot{\infty} 0 \text { है } \\
\text { ज्ञ } \\
x\end{array}$ & & \\
\hline ت্ & & & \multicolumn{2}{|c|}{$\begin{array}{l}\text { Analyzing and Interpreting Data (4) } \\
\text { Engaging in Argument from Evidence (7) }\end{array}$} \\
\hline
\end{tabular}




\begin{tabular}{|c|c|c|c|c|}
\hline 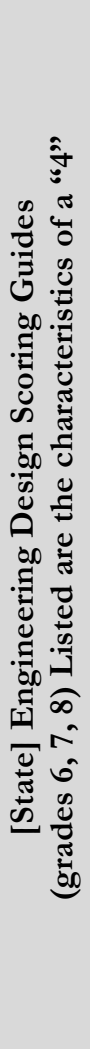 & $\begin{array}{l}\text { Identifying and } \\
\text { Defining a Problem } \\
\text { to be Solved } \\
\text { Based on observations and } \\
\text { scientific principles, } \\
\text { formulate the statement of } \\
\text { a practical problem that } \\
\text { can be addressed through } \\
\text { the process of engineering } \\
\text { design. } \\
\text { - Describes a problem } \\
\text { to be solved through } \\
\text { the process of } \\
\text { engineering design. } \\
\text { - Describes relevant } \\
\text { background } \\
\text { information and } \\
\text { science principles } \\
\text { that relate to the } \\
\text { problem. } \\
\text { - Identifies criteria and } \\
\text { constraints to be } \\
\text { applied to the } \\
\text { solution. }\end{array}$ & $\begin{array}{l}\text { Generating Possible } \\
\text { Solutions } \\
\text { Evaluate and select an } \\
\text { engineering solution from a } \\
\text { range of possible options, } \\
\text { and defend that solution for } \\
\text { testing using trade-offs, } \\
\text { criteria, and constraints. } \\
\text { - Describes possible } \\
\text { engineering } \\
\text { solutions to the } \\
\text { problem identified. } \\
\text { - Evaluates the } \\
\text { proposed solutions } \\
\text { in terms of design } \\
\text { and performance } \\
\text { criteria, constraints, } \\
\text { priorities, and trade- } \\
\text { offs. } \\
\text { - Selects and explains } \\
\text { why a proposed } \\
\text { solution was } \\
\text { selected for testing } \\
\text { based on criteria } \\
\text { and constraints. }\end{array}$ & $\begin{array}{l}\text { Testing Solution(s) } \\
\text { and Collecting Data } \\
\text { Test solution(s) by } \\
\text { collecting, organizing, and } \\
\text { displaying data to facilitate } \\
\text { the analysis and } \\
\text { interpretation of test } \\
\text { results. } \\
\text { - Constructs a } \\
\text { solution that } \\
\text { adequately addresses } \\
\text { the criteria and } \\
\text { constraints and is } \\
\text { appropriate for } \\
\text { testing } \\
\text { - Collects accurate } \\
\text { data relevant to the } \\
\text { criteria and } \\
\text { constraints using } \\
\text { appropriate } \\
\text { techniques to test or } \\
\text { analyze a solution. } \\
\text { - Displays data that is } \\
\text { complete and } \\
\text { facilitates evaluation } \\
\text { of the solution. }\end{array}$ & $\begin{array}{l}\text { Analyzing and } \\
\text { Interpreting Results } \\
\text { Summarize and analyze } \\
\text { data, evaluate the proposed } \\
\text { solution in terms of design } \\
\text { criteria and constraints and } \\
\text { trade-offs and suggest design } \\
\text { improvements. } \\
\text { - Evaluates the tested } \\
\text { solution in terms of } \\
\text { design and } \\
\text { performance criteria, } \\
\text { constraints, and } \\
\text { identifies priorities } \\
\text { and trade-offs. } \\
\text { - Describes to what } \\
\text { extent the solution } \\
\text { addressed the criteria } \\
\text { and constraints. } \\
\text { - Identifies and } \\
\text { explains possible } \\
\text { design } \\
\text { improvements. }\end{array}$ \\
\hline 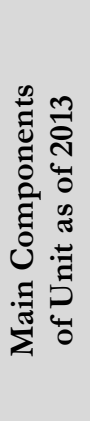 & \multicolumn{4}{|c|}{$\begin{array}{l}\text { » Twenty-four lessons } \\
\text { » Lab packet pages to accompany all non-work sample lessons } \\
\text { » Engineering design work sample packet broken into four distinct steps in alignment with the [State] } \\
\text { Scoring Guide } \\
\text { »Student version of the [City] Stormwater Management Manual with planting guide } \\
\text { »Various [City] maps of watersheds, campuses, etc. } \\
\text { » Assessments including pre- and post-assessments, formative assessments, self-assessments, and } \\
\text { explanation of alignment to [State] State standards }\end{array}$} \\
\hline
\end{tabular}




\section{Standard: MS-ESS2 Earth's Systems}

Performance Expectation: MS-ESS2-2. Construct an explanation based on evidence for how geoscience processes have changed Earth's surface at varying time and spatial scales.

Performance Expectation: MS-ESS2-4. Develop a model to describe the cycling of water through Earth's systems driven by energy from the sun and the force of gravity.

\section{Standard: MS-ESS3 Earth and Human Activity}

Performance Expectation: MS-ESS3-2. Analyze and interpret data on natural hazards to forecast future catastrophic events and inform the development of technologies to mitigate their effects. Performance Expectation: MS-ESS3-3. Apply scientific principles to design a method for monitoring and minimizing a human impact on the environment.

\section{Standard: MS-LS2 Ecosystems: Interactions, Energy, and Dynamics}

Performance Expectation: MS-LS2-5. Evaluate competing design solutions for maintaining biodiversity and ecosystem services.

\section{Standard: MS-ETS1 Engineering Design}

Performance Expectation: MS-ETS1-1. Define the criteria and constraints of a design problem with sufficient precision to ensure a successful solution, taking into account relevant scientific principles and potential impacts on people and the natural environment that may limit possible solutions.

Performance Expectation: MS-ETS1-2. Evaluate competing design solutions using a systematic process to determine how well they meet the criteria and constraints of the problem.

Performance Expectation: MS-ETS1-3. Analyze data from tests to determine similarities and differences among several design solutions to identify the best characteristics of each that can be combined into a new solution to better meet the criteria for success.

Performance Expectation: MS-ETS1-4. Develop a model to generate data for iterative testing and modification of a proposed object, tool, or process such that an optimal design can be achieved.

\section{Content Standard: $6.3 \mathrm{~S} .2$}

Organize and display relevant data, construct an evidence-based explanation of the results of an investigation, and communicate the conclusions.

\section{Content Standard: 6.3S.3}

Explain why if more than one variable changes at the same time in an investigation, the outcome of the investigation may not be clearly attributable to any one variable.

\section{Content Standard: 6.4D.1}

Define a problem that addresses a need and identify science principles that may be related to possible solutions.

\section{Content Standard: 6.4D.2}

Design, construct, and test a possible solution to a defined problem using appropriate tools and materials. Evaluate proposed engineering design solutions to the defined problem.

\section{Content Standard: 6.2E.1}

Explain the water cycle and the relationship to landforms and weather 


\section{Appendix C}

Spring 2013

\section{Watershed \& Engineering Design Pre-Assessment}

This pre-assessment will not affect your grade. When you come across something unfamiliar, please read all of the options and make your best guess. Do not write on this test packet.

Select the option that best completes the sentence or answers the question.

1. Watersheds are found
a. in cities.
b. anywhere there are people.
c. in wilderness areas.
d. in dry locations.
e. in all of the above options.

2. Which item best illustrates a watershed?

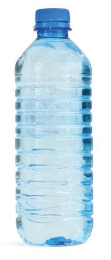

a.

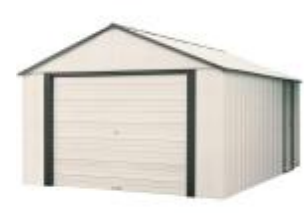

b.

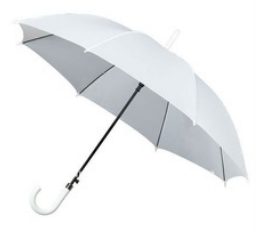

c.

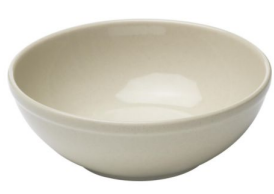

d.

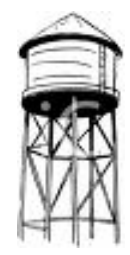

e.

3. Which option best describes the two elements most responsible for the movement of water within a watershed?
a. Sun and moon
b. Moon and wind
c. Wind and gravity
d. Gravity and sun
e. none of the above options.

4. Groundwater is
a. water that sits on the ground.
b. water that is stored on the ground.
c. water that is stored underground.
d. water in streams and rivers.
e. all of the above options.

5. All together, human development such as houses, roads, stores, and factories, has
a. not affected watersheds.
b. made watersheds healthier.
c. made watersheds less healthy.
d. created watersheds.
e. happened only outside of watershed areas. 


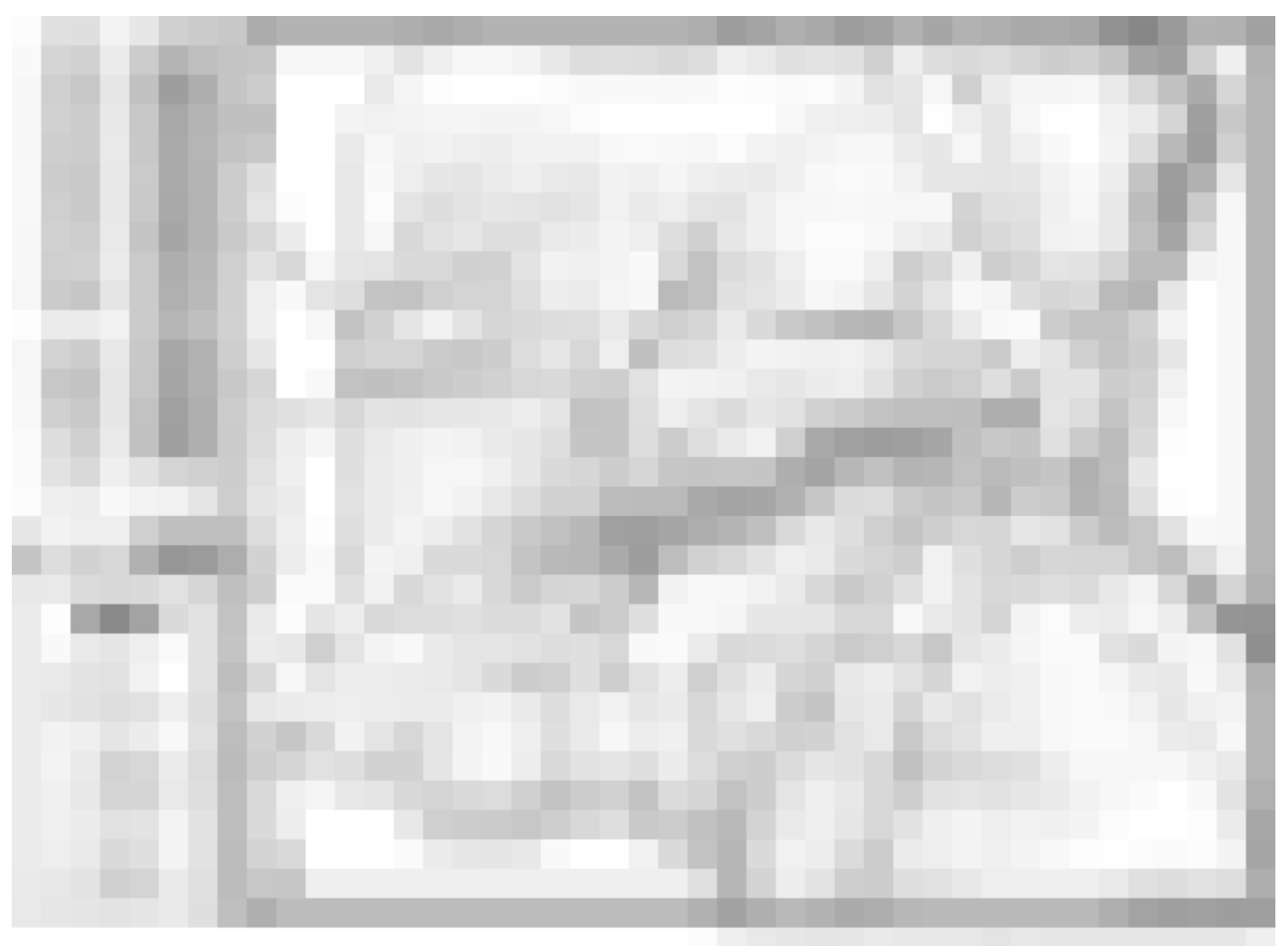

6. According to the map above, which creeks drain into Local Lake?

\begin{tabular}{l|crcc|c} 
a. & A & Creek and & B & Creek \\
b. & C & Creek and & & A & Creek \\
c. & D & Creek and & C & Creek \\
d. & E & Creek and & D & Creek \\
e. & B & Creek and & E & Creek
\end{tabular}

7. Much of the rainwater that falls on our community makes its way to Local Lake, and from there, to
a. the Nearby River.
b. the Columbia River.
c. the Pacific Ocean.
d. all of the above options.
e. none of the above options.

8. When rain falls in the city, which of the following is not a path it might take?
a. Street $\rightarrow$ C Creek $\rightarrow$ Local Lake
b. Tree $\rightarrow$ evapotranspiration $\rightarrow$ cloud
c. Lawn $\rightarrow$ Local Lake $\rightarrow$ A Creek
d. Soil $\rightarrow$ groundwater $\rightarrow$ D Creek
e. Roof $\rightarrow$ drainage ditch $\rightarrow$ F $\quad$ Creek 
9. After weeks of dry weather, the water flowing in creeks
a. seeps in from groundwater.
b. pours in from underground rivers.
c. flows in from rivers on the surface.
d. is piped in from water storage tanks.
e. condenses from the atmosphere.

10. When heavy rain falls on a paved street,

a. most of it stays there until it evaporates.

b. most of it is absorbed by the pavement.

c. most of it sinks into the ground through the pavement.

d. most of it gets carried away by vehicles.

e. most of it flows off the road into ditches or storm drains.

11. Look to the labeled picture below: which option lists all of the impervious surfaces?

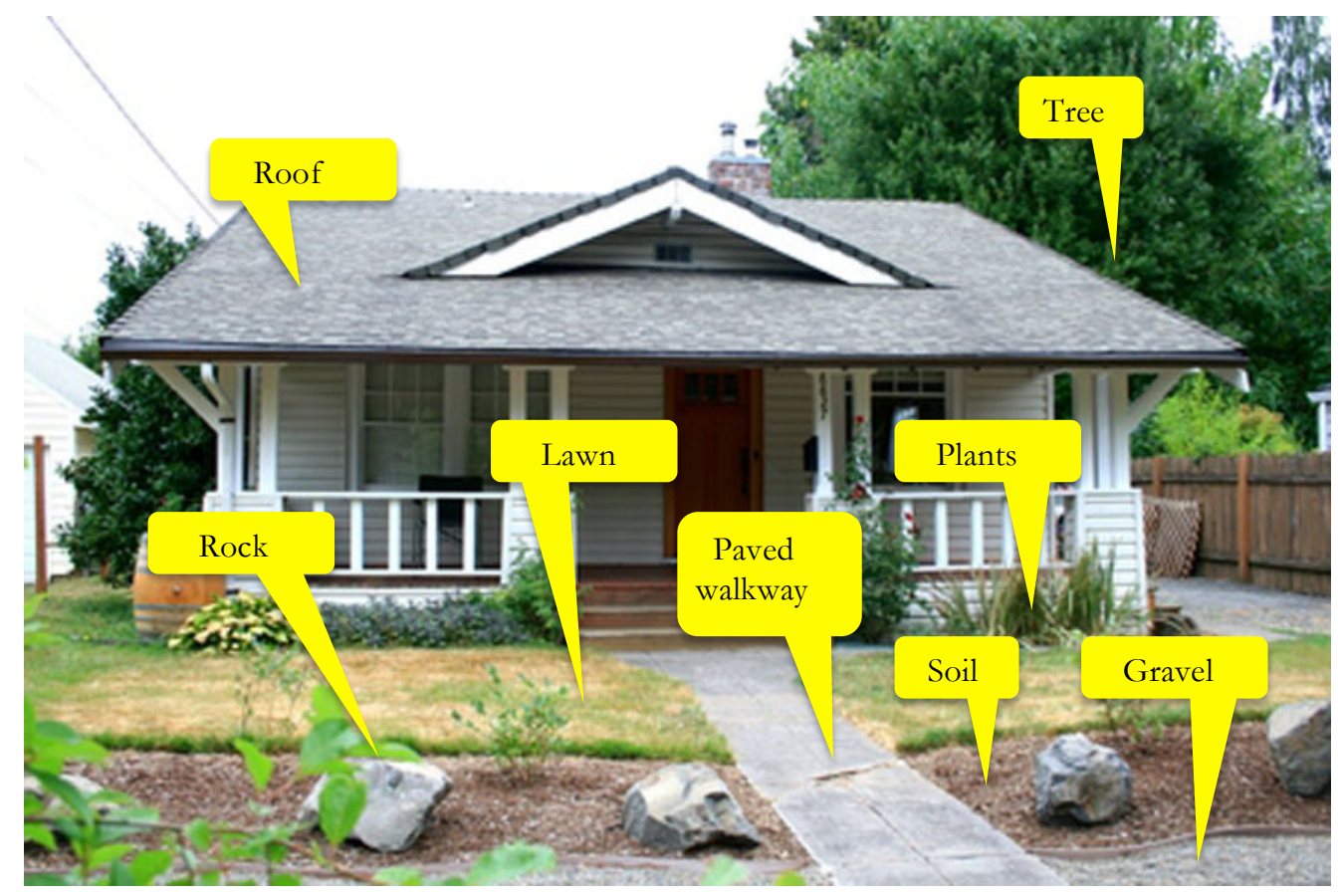
a. Paved walkway, soil, lawn, gravel
b. Roof, paved walkway, rock
c. Lawn, plants, tree
d. Soil, gravel, rock, roof
e. Plants, soil, tree, rock, gravel, lawn

12. Which of the following is not an impact of impervious surface?
a. The lake has less nutrients for algae
b. Creeks that dry up in summer
c. Loss of habitat for plants and animals
d. Erosion in streams
e. Water entering streams is polluted 
13. Sitting on a desk are the items below. Which of these are examples of technology?

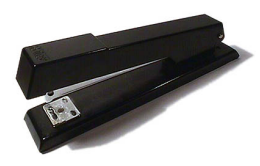

stapler

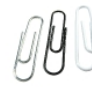

paperclips

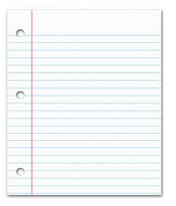

lined paper

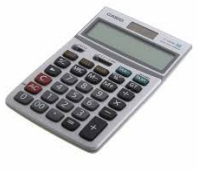

calculator

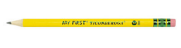

pencil

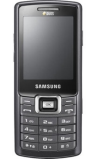

cell phone
a. The cell phone and calculator
b. The cell phone, calculator, and stapler
c. The cell phone, calculator, stapler, and paper clips
d. The cell phone, calculator, stapler, paper clips, and pencil
e. All are examples of technology

For questions 14 - 17 refer to Gloria's Pugh chart below.

\begin{tabular}{|c|c|c|c|c|c|}
\hline $\begin{array}{l}\text { PROBLEM TO BE } \\
\text { SOLVED: }\end{array}$ & \multicolumn{5}{|c|}{ Rabbits keep eating the vegetables that I am growing for my family } \\
\hline $\begin{array}{l}\text { Evaluate each } \\
\text { solution against each } \\
\text { criterion and } \\
\text { constraint } \\
\text { 0: Does not meet } \\
\text { 1: Meets a little bit } \\
\text { 2: Meets halfway } \\
\text { 3: Completely meets }\end{array}$ & 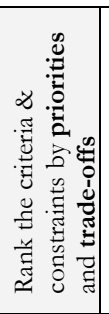 & $\begin{array}{l}\text { SOLUTION A } \\
\text { Build a } 1 \text { meter } \\
\text { wooden fence } \\
\text { mmmmmmm }\end{array}$ & $\begin{array}{l}\text { SOLUTION B } \\
\text { Only grow } \\
\text { plants that } \\
\text { rabbits } \\
\text { don't like to } \\
\text { eat }\end{array}$ & 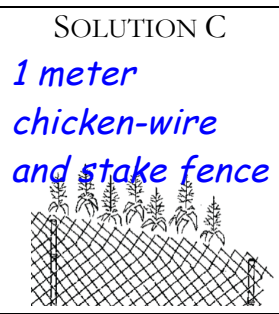 & $\begin{array}{l}\text { SOLUTION D } \\
\text { Set rabbit } \\
\text { traps and let } \\
\text { them out } \\
\text { somewhere } \\
\text { else }\end{array}$ \\
\hline $\begin{array}{l}\text { CRITERION } 1 \\
\text { Have homegrown } \\
\text { vegetables to eat }\end{array}$ & 1 & 3 & 1 & 3 & 2 \\
\hline $\begin{array}{r}\text { CRITERION } 2 \\
\text { Easy to maintain }\end{array}$ & 4 & 3 & 3 & 2 & 1 \\
\hline $\begin{array}{l}\text { CRITERION } 3 \\
\text { Nice enough to } \\
\text { look at }\end{array}$ & 5 & 3 & 3 & 2 & 2 \\
\hline $\begin{array}{l}\text { CONSTRAINT } 1 \\
\text { Won't hurt the } \\
\text { rabbits }\end{array}$ & 3 & 3 & 3 & 3 & 2 \\
\hline $\begin{array}{l}\text { CONSTRAINT } 2 \\
\text { Is not very } \\
\text { expensive }\end{array}$ & 2 & 1 & 2 & 3 & 2 \\
\hline $\begin{array}{l}\text { After scoring each solt } \\
\text { against each criterion } \\
\text { constraint, total the sc } \\
\text { the bottom } \Rightarrow\end{array}$ & & 13 & 12 & 13 & 9 \\
\hline
\end{tabular}

14. In the above Pugh chart, solution A earned a score of 1 for constraint 2 . This means building a 1-meter wooden fence
a. "Does not meet" the constraint of "Is not very expensive"
b. "Meets a little bit" the constraint of "Is not very expensive"
c. "Meets halfway" the constraint of "Is not very expensive"
d. "Completely meets" the constraint of "Is not very expensive"
e. is the best solution 
15. According to the Pugh chart, Gloria should choose the chicken wire fence. Why?

a. It had the highest total score

b. It had the lowest total score

c. It scored higher than solution $A$ in constraint 2 , which had high priority

d. It scored higher than solution $\mathrm{D}$ in criterion 2, which had low priority

e. It came in second place in criterion 3

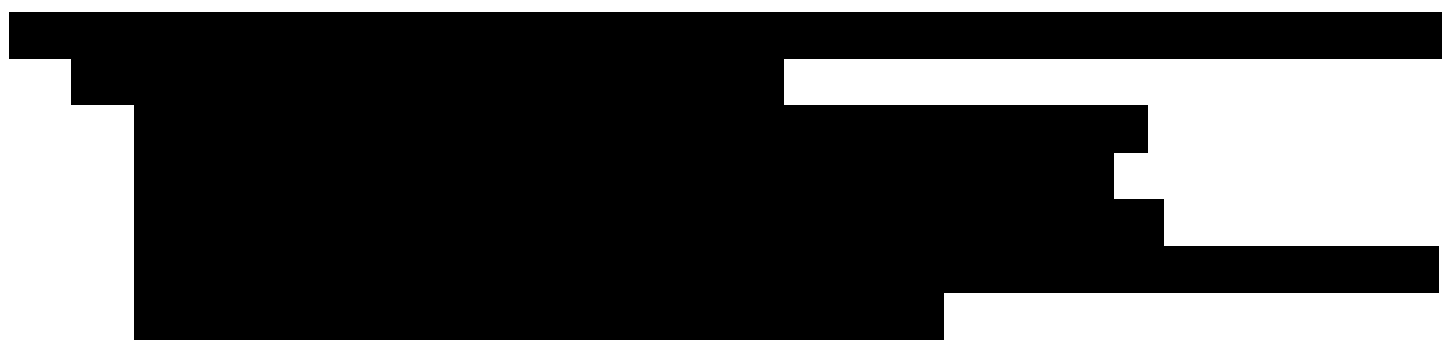

17. According to the chart, Gloria believes that

a. Solution $\mathrm{C}$ would be harder to maintain that Solution $\mathrm{A}$

b. Solution B is more expensive than Solution A

c. Solution $\mathrm{D}$ is less attractive than solution $\mathrm{C}$

d. Solution B is more dangerous for the rabbits than Solution D

e. All of the solutions would allow Gloria to grow enough vegetables for her family

18. Look to the half sheet of paper with a gray shape and grid. Follow the instructions and record your answer by selecting one of the options below.
a. 30 square meters
b. 40 square meters
c. 50 square meters
d. 60 square meters
e. It is impossible to estimate without more information 
The gray shape below represents the aerial view of a building surrounded by grass. Find the area of the impervious surface in square meters $\left(\mathrm{m}^{2}\right)$.

You can draw and write on this paper.

Use your answer to choose the answer on the test packet that most closely matches your answer.

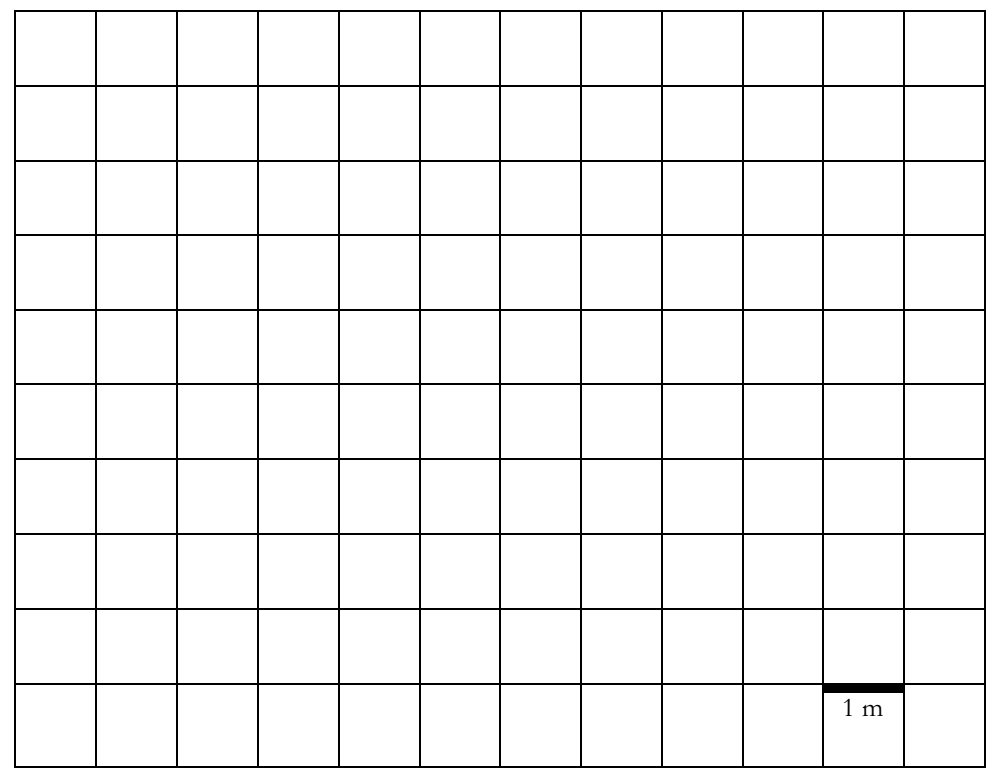

Work space

Total area of shape: square meters, or $\mathrm{m}^{2}$ 